\title{
Impact of the 2011 Southern U.S. Drought on Ground-Level Fine Aerosol Concentration in Summertime*
}

\author{
YUXUAN WANG \\ Department of Marine Science, Texas A\&M University, Galveston, Texas, and Ministry of Education Key \\ Laboratory for Earth System Modeling, Center for Earth System Science, Tsinghua University, Beijing, \\ China, and Department of Atmospheric Science, Texas A\&M University, College Station, Texas \\ Yuanyu Xie, Libao Cai, Wenhao Dong, AND Qiandian Zhang \\ Ministry of Education Key Laboratory for Earth System Modeling, Center for Earth System Science, \\ Tsinghua University, Beijing, China \\ LIN ZHANG \\ Laboratory for Climate and Ocean-Atmosphere Sciences, Department of Atmospheric and \\ Oceanic Sciences, School of Physics, Peking University, Beijing, China
}

(Manuscript received 10 July 2014, in final form 17 October 2014)

\begin{abstract}
This study investigates the impacts of the 2011 severe drought in the southern United States on ground-level fine aerosol $\left(\mathrm{PM}_{2.5}\right)$ concentrations in the summer. The changes in surface concentrations and planetary boundary layer (PBL) budget of $\mathrm{PM}_{2.5}$ between June 2010 (near-normal rainfall) and June 2011 (severe drought) are quantified using surface observations and the GEOS-Chem model. Observations show an average enhancement of $26 \%\left(p<10^{-4}\right)$ in total $\mathrm{PM}_{2.5}$ over the southern U.S. (SUS) region during the drought, which is largely attributed to a $\sim 120 \%$ increase in organic carbon (OC). Over Texas (TX) under extreme drought conditions, surface $\mathrm{PM}_{2.5}$ shows a mean decrease of $10.7 \%(p<0.15)$, which is mainly driven by a decrease of $26 \%(p<0.03)$ in sulfate. Model simulations reproduce the observed relative changes in total $\mathrm{PM}_{2.5}$, OC, and sulfate during the drought. The model correctly identifies $\mathrm{OC}$ as the major contributor to the overall $\mathrm{PM}_{2.5}$ increase over SUS and sulfate as the key driver of the $\mathrm{PM}_{2.5}$ decrease over TX. Budget analysis suggests that increased OC emissions from wildfires $\left(+58 \mathrm{ktCmonth}^{-1}\right)$, enhanced SOA production $\left(+1.1 \mathrm{kt} \mathrm{C} \mathrm{month}^{-1}\right)$, and transboundary inflow from Mexico $\left(+8.6 \mathrm{kt} \mathrm{C} \mathrm{month}^{-1}\right)$ are major contributors to the increase in atmospheric OC contents over SUS. Over TX, a 70\% decrease of aqueous-phase oxidation of sulfate, driven by decreasing low clouds, outweighs the combined effects of reduced wet deposition and decreased outflow as the key driver of sulfate decrease both at the surface and within the PBL.
\end{abstract}

\section{Introduction}

Atmospheric fine particulate matter $\left(\mathrm{PM}_{2.5}\right)$ has a large impact on the climate system, air quality, and human health. Spatiotemporal variations of $\mathrm{PM}_{2.5}$ are influenced

\footnotetext{
* Supplemental information related to this paper is available at the Journals Online website: http://dx.doi.org/10.1175/JAS-D-140197.s1.

Corresponding author address: Yuxuan Wang, 200 Seawolf Parkway, P.O. Box 1675, Galveston, TX 77553.

E-mail:wangyx@tamug.edu
}

not only by emissions but also by meteorological conditions. Drought is an unusual meteorological condition affecting both society and the natural environment. The meteorological conditions during the drought include rainfall deficit, higher surface temperatures, reduced cloud fractions, and associated changes in circulation patterns. These changes can exert large impacts on concentrations and distributions of atmospheric aerosols by affecting their scavenging, chemistry, and sources. Rainfall decreases affect wet removal of atmospheric particles, especially in regions with a smaller precipitation base (Dawson et al. 2007). Higher temperatures favor the formation of sulfate and promote partitioning of ammonium nitrate and 
organics into the gas phase, while lower cloud fraction and lower relative humidity reduce aqueous-phase $\mathrm{SO}_{2}$ oxidation to sulfate (Seinfeld and Pandis 2012). Water and heat stress will increase the mortality rate of trees (Allen et al. 2010), affecting emissions of biogenic volatile organic compounds (BVOCs) and dry deposition fluxes of particles through leaf absorption. Reduced soil moisture not only favors mobilization of soil and dust but also reduces PM deposition onto the surface (Räsänen et al. 2012). In addition, wildfires are expected to become more frequent under drought conditions, releasing large amounts of aerosol precursors and carbonaceous aerosols into the atmosphere. The complex dependence of $\mathrm{PM}_{2.5}$ species on meteorological parameters needs to be considered when assessing the drought impact on PM air quality.

Several studies have evaluated the impacts of drought on aerosol loadings in the atmosphere and the resulting effects on public health (Tosca et al. 2010; Vijayakumar et al. 2012). Dust emissions over the sub-Saharan and Sahel regions in North Africa are found to be over 3 times higher during the drought periods than during the predrought periods, resulting in enhanced westward outflow of dust plumes evidently observed at the Barbados site (Middleton 1985; Prospero and Nees 1986). Marlier et al. (2013) assessed the impact of El Niñoinduced droughts on surface $\mathrm{PM}_{2.5}$ over Southeast Asia using satellite observations and chemical transport models (CTMs). They suggested that carbonaceous aerosols from fire activities during strong drought years are responsible for the exceedance of annual mean $\mathrm{PM}_{2.5}$ over $200 \mu \mathrm{g} \mathrm{m}^{-3}$. Two hundred additional days were identified as unhealthy owing to $\mathrm{PM}_{2.5}$ exposure during the drought years. Exposure to particles from drought-induced fire emissions is shown to significantly affect the respiratory system of children and increase hospitalization by $1.2 \%-$ 267\% (Smith et al. 2014). The State of the Air 2014 report released by the U.S. Lung Association notes the potential air quality degradation over southern California due to drought-induced increases in dust and wildfires, despite long-term efforts of reducing anthropogenic emissions over this region.

Drought has widespread influence over the continental United States (Svoboda et al. 2002). For example, in 2011, there was an extensive drought extending almost continuously across the southern United States from Arizona to North Carolina (NCDC 2014). The 2011 southern U.S. drought, attributed to coincidence of La Niña and decadal or multidecadal atmospheric oscillation, started in early October 2010 and extended to early winter of 2012. It was record breaking in terms of duration and severity (Nielsen-Gammon 2012; Combs 2012; Winguth and Kelp 2013; Romm 2011; Kerr 2012).
More than 14 states were affected by this drought, especially New Mexico, Texas, and Oklahoma. In the most influenced region in Texas, annual precipitation dropped by more than $50 \%$ from $667 \mathrm{~mm}$ (1895-2011 climatology) to $267 \mathrm{~mm}$ for the 2011 water year (October 2010-September 2011) (Long et al. 2013). The composite drought severity index (Svoboda et al. 2002) provided by the U.S. Drought Monitor (www.droughtmonitor.unl.edu) shows that until late June 2011 , more than $88 \%$ areas in the southern and $84 \%$ in the southeastern United States experienced drought conditions of different extent, and nearly half of the areas were under the most severe D4 type (exceptional drought characterized by intensity). Given the diversity of land cover types and PM sources in the southern United States, the impacts of the 2011 severe drought on PM air quality are potentially important over this region but have yet to be characterized and quantified.

Climate predictions suggest an increasing frequency in droughts and drought intensity over the U.S. continent, particularly over the southern and western United States (Dai 2013). It is essential to understand the impact of the present droughts on $\mathrm{PM}_{2.5}$ in order to evaluate the potential changes of surface air quality in response to increasing droughts in the future. In this study, we present a quantitative assessment of the impacts of the 2011 southern U.S. drought on the distribution and budget of surface $\mathrm{PM}_{2.5}$ in the summertime. June 2011 was selected as the study period by which drought reached its peak severity. Section 2 describes the meteorological features of June 2011 and compares them with those of the 10-yr-mean climatology and June 2010. Section 3 introduces surface observations and the GEOSChem model used in the study, with a focus on droughtinduced variations of natural emissions simulated by the model. In section 4 we analyze the observed changes of $\mathrm{PM}_{2.5}$ and its major components under drought conditions and evaluate the model's ability in reproducing those observed changes. In sections 5 and 6, the drought's impact on important $\mathrm{PM}_{2.5}$ components including $\mathrm{OC}$ and sulfate are quantified through budget analysis. Discussion and conclusion are given in section 7 .

\section{Meteorology conditions during the 2011 drought}

Analysis of meteorological conditions over the southern United States was conducted on the basis of the reanalysis datasets from Modern Era Retrospective Analysis for Research and Applications (MERRA). MERRA products are based on Goddard Earth Observing System (GEOS) Data Assimilation System (DAS) that include the National Aeronautics and Space Administration (NASA)'s Earth Observing System (EOS) satellite observations for weather and climate research. The special 

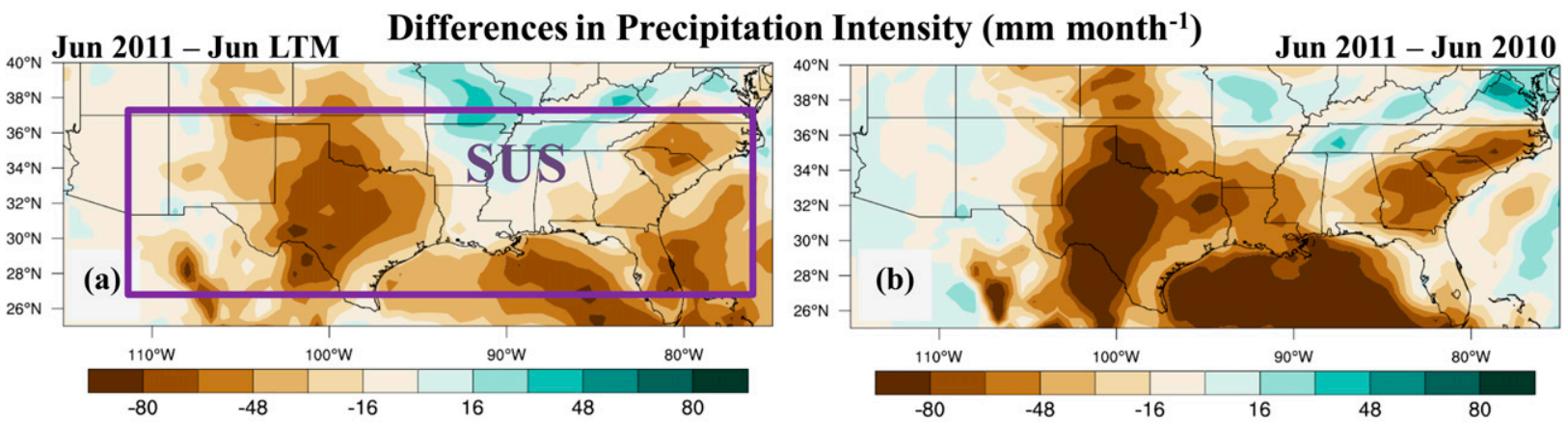

Differences in Number of Precipitation Days (days)
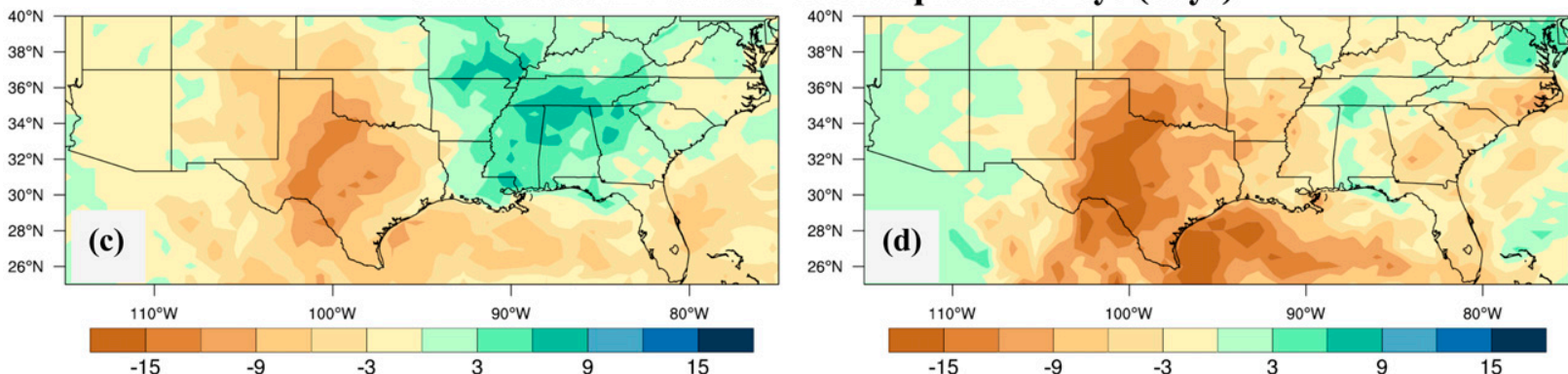

Differences in Temperature (K)
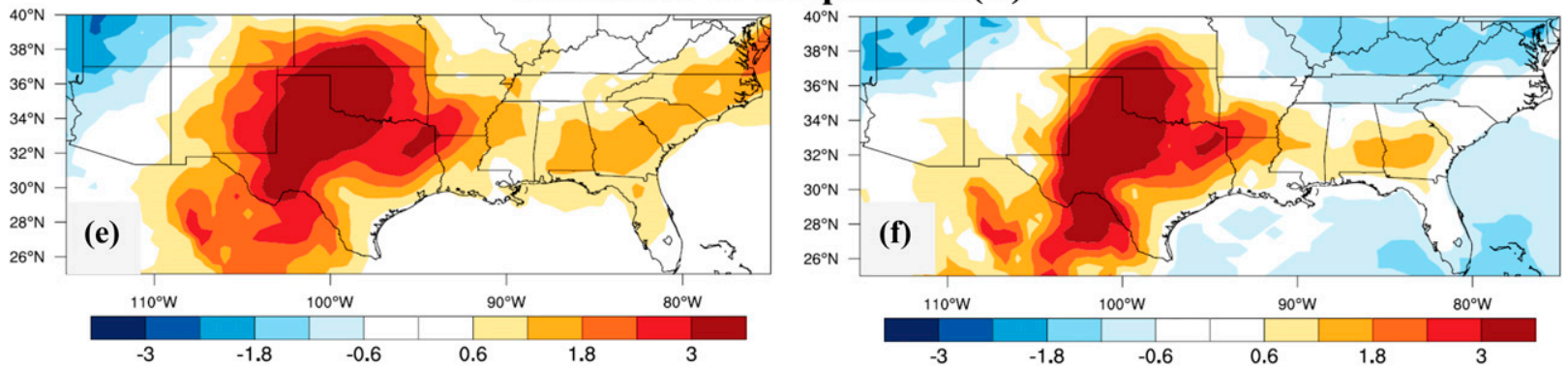

FIG. 1. (a),(b) Differences in monthly precipitation, (c),(d) the number of days with precipitation $>2.4 \mathrm{~mm} \mathrm{day}^{-1}$, and (e),(f) surface temperature between (left) June 2011 and June LTM and (right) June 2011 and June 2010. Data are from MERRA. The purple box in (a) denotes the SUS domain.

focus of MERRA on the hydrological cycle provides spatially and temporally consistent datasets in the precipitation, temperature, moisture, and transport fields (Rienecker et al. 2011). In this section, major changes of meteorological variables during the drought_-including precipitation, temperature, wind speed, as well as sea level pressure (SLP) - are described based on MERRA.

\section{a. Precipitation and temperature change}

Precipitation decrease is the main meteorological feature of drought. Long-term time series of surface precipitation in the southern United States from MERRA indicate that 2011 had the least rainfall during the past $10 \mathrm{yr}$ (2003-12) (see Fig. S1 in the supplementary material file JAS-D-14-0197s1). Compared with the deseasonalized long-term-mean precipitation from 2003 to 2012 (LTM herein), 10 months in 2011 showed negative precipitation anomalies, among which wet summer months, particularly June, had the largest precipitation decrease. Therefore, June 2011 was selected as the study period of severe drought conditions. Based on the spatial pattern of precipitation deficit between June 2011 and June LTM shown in Fig. 1a, the southern U.S. domain (SUS) is defined as the study region $\left(27^{\circ}-37^{\circ} \mathrm{N}, 112^{\circ}-\right.$ $75^{\circ} \mathrm{W}$; Fig. 1a). LTM monthly total precipitation over SUS was $96.7 \mathrm{~mm}$ for the month of June. In June 2010, the domain-mean monthly total precipitation was $101.1 \mathrm{~mm}$-close to LTM. By comparison, the amount of precipitation in June 2011 was $67.4 \mathrm{~mm}-30 \%$ lower than LTM and 33\% lower than June 2010. June 2010 was selected as a period of normal conditions on the basis of two considerations: first, June 2010 had nearnormal rainfall, which was within $5 \%$ of LTM; second, anthropogenic emissions were subject to little change from 2010 to 2011 compared with other years of normal conditions (e.g., 2005). 
Changes in the amount of precipitation between June 2011 and LTM (June 2011 minus LTM) and those between June 2011 and 2010 (June 2011 minus June 2010) are shown in Figs. 1a and 1b, respectively. Compared with LTM, the states of Texas, Oklahoma, and New Mexico saw the largest precipitation reduction in 2011. The precipitation decreased to $70 \mathrm{~mm} \mathrm{month}^{-1}$ in Texas (58\% decrease compared to June LTM level). Over some parts of New Mexico, with LTM precipitation being less than $50 \mathrm{~mm}$ month $^{-1}$, the relative decrease ranged from $90 \%$ to $96 \%$. Wetter regions along the Southeast coast also experienced rainfall decreases by $\sim 40 \mathrm{~mm} \mathrm{month}^{-1}[\sim(10 \%-30 \%)]$. Precipitation changes in June 2011 compared to June 2010 (Fig. 1b) share similar patterns as those derived from the LTM; the spatial correlation between Figs. $1 \mathrm{a}$ and $1 \mathrm{~b}$ is 0.86 . Relative rainfall decreases over Texas and New Mexico were more than $50 \%$, while those over the Southeast coast were comparatively smaller at approximately $30 \%-40 \%$. The similarity between Figs. 1a and $1 \mathrm{~b}$ indicates that it is appropriate to select June 2010 as a month of near-normal precipitation.

The frequency of precipitation also changed significantly under the drought conditions. Figures $1 \mathrm{c}$ and $1 \mathrm{~d}$ show the change in the number of precipitation days in June 2011 as compared to LTM and June 2010, respectively. A threshold of $2.4 \mathrm{~mm}$ of precipitation per day, the smallest amount of precipitation numerically recorded, is used for distinguishing days with and without precipitation (Dai et al. 1999). Compared with June LTM and June 2010, the mean number of precipitation days in June 2011 was $\sim 18 \%$ lower over SUS as a whole. Over northern Texas, the number of precipitation days decreased from around 20 days under the normal conditions to less than 6 days in June 2011. The corresponding decrease over the southeastern states was from more than 25 days to about 20 days.

Temperatures were ubiquitously higher over the drought-affected regions. The domain-average temperature is $299.3 \mathrm{~K}$ for LTM and $299.9 \mathrm{~K}$ in June 2010. During the 2011 drought, temperatures increased by $1.2 \mathrm{~K}$ compared to LTM. The spatial distribution of temperature differences during June 2011 is shown in Fig. 1e (compared to LTM) and Fig. 1f (compared to June 2010). Large temperature increases were found over most of Texas, which saw a monthly-mean surface temperature of $303 \mathrm{~K}$-about $3 \mathrm{~K}$ higher than that in LTM and June 2010. The largest increase of $5 \mathrm{~K}$ was close to the records of the warmest summer over the U.S. continent (Nielsen-Gammon 2012). Over the Southeast region, the temperature increase was less significant at around $1 \mathrm{~K}$. Higher surface temperature was expected to increase the PBL height. Over northern Texas, where temperature increase was most significant, the PBL height increased by nearly a factor of 2 during the drought. The increase of the PBL over the Southeast coast region was about $30 \%$.

\section{b. Circulation pattern and wind field change}

The changes of precipitation and temperature are strongly related to variations in the circulation patterns during the drought. SLP and mean circulation patterns depicted by $10-\mathrm{m}$ wind vectors are presented in Fig. 2. The LTM circulation patterns in June (Fig. 2a) were determined by the Bermuda high pressure system over the East Coast and a low pressure system over the Great Plains. South or southeast winds blew onshore from the Gulf of Mexico with an average speed of $4 \mathrm{~m} \mathrm{~s}^{-1}$, while strong westerly winds exceeding $3 \mathrm{~m} \mathrm{~s}^{-1}$ prevailed over Arizona and New Mexico. Winds were less strong over the Southeast. The changes in SLP and winds during June 2011 are displayed in Figs. 2b and 2c as compared to LTM and June 2010, respectively. SLP in June 2011 was lower by $3-5 \mathrm{hPa}$ than that in LTM (Fig. 2b) and June 2010 (Fig. 2c) across the southern High Plains. The shifted surface trough of the low pressure system across southeast Colorado and New Mexico is attributed to have caused the drier, warmer, and windier conditions in the regions southward (Liu et al. 1998; Seager et al. 2014). Meanwhile, westerly winds were stronger by $\sim 1-2 \mathrm{~m} \mathrm{~s}^{-1}$ over New Mexicoalmost double those of LTM. Southerly winds over central and south Texas also showed an increase of $\sim 1-2 \mathrm{~m} \mathrm{~s}^{-1}$ during the drought.

To summarize, June 2011 presents the peak drought conditions in terms of precipitation deficit and surface temperature increases, while June 2010 represents the near-normal conditions by comparison to LTM. The changes of precipitation, temperature, SLP, wind speeds, and the PBL height during the drought are expected to exert complex influences on concentrations and distribution of surface $\mathrm{PM}_{2.5}$.

\section{Observation data and model}

\section{a. Surface observations}

Surface $\mathrm{PM}_{2.5}$ observations from Interagency Monitoring of Protected Visual Environments (IMPROVE) (Malm et al. 1994) and Environmental Protection Agency (EPA) networks are used in this study. Surface $\mathrm{PM}_{2.5}$ and its species are routinely measured every 3 days at $\sim 200$ IMPROVE sites nationwide with quality assurance procedures. The EPA Air Quality System (EPA-AQS) (http:// www.epa.gov/ttn/airs/airsaqs/) provides daily mean total $\mathrm{PM}_{2.5}$ concentrations at more than 1000 sites following Federal Reference Method (FRM). Speciated daily 

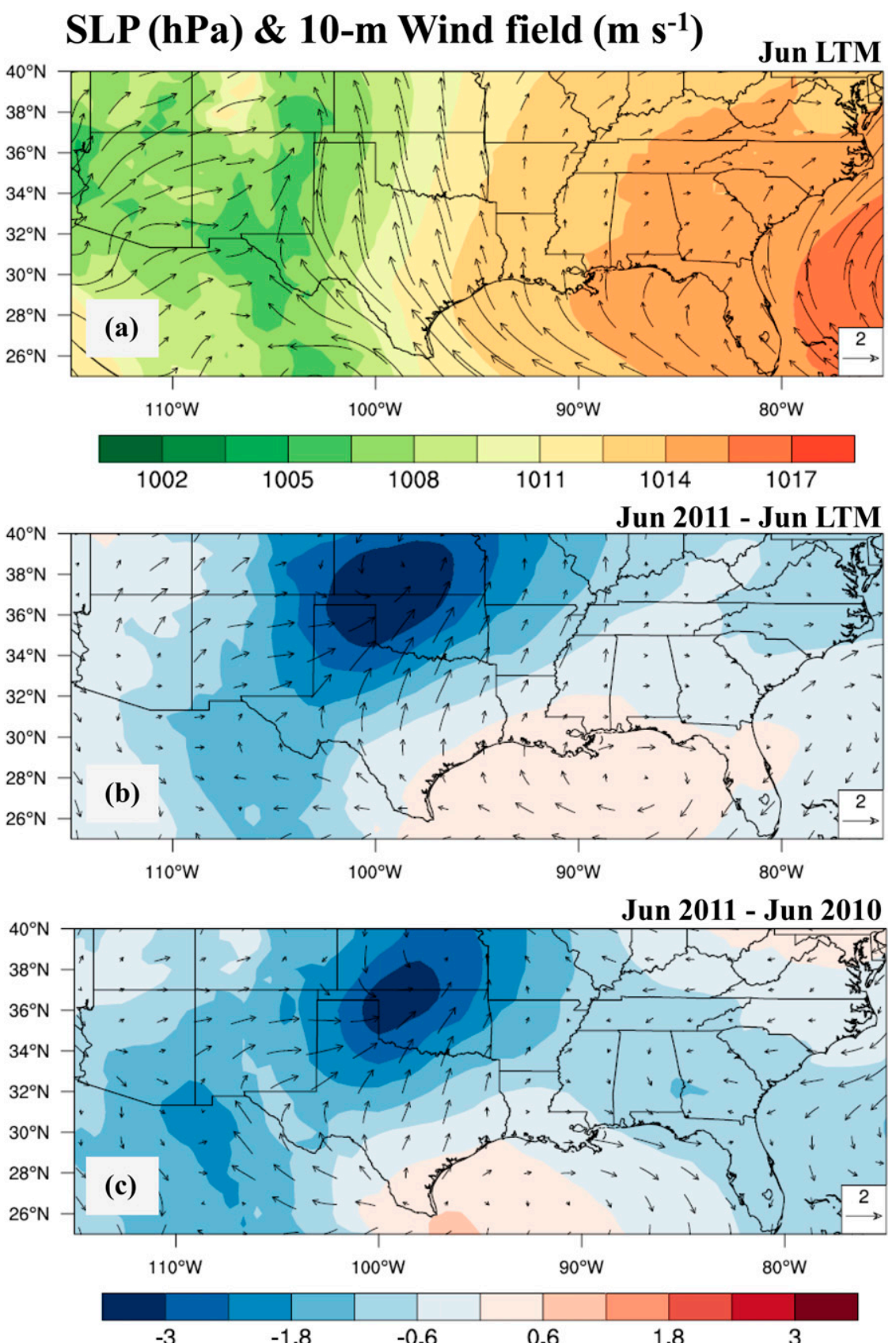

FIG. 2. Sea level pressure (color shading) and 10-m wind fields (vectors) for (a) June LTM, (b) differences between June 2011 and LTM, and (c) differences between June 2011 and June 2010. Data are from MERRA.

average $\mathrm{PM}_{2.5}$ are provided by Speciation Trends Network (STN) at about 200 sites in the United States that are mainly located in urban and suburban areas. Observations from both the IMPROVE and EPA datasets are combined for the purpose of wider spatial coverage and representativeness. The site locations within the SUS domain are shown in Fig. S2 in the supplementary material. Although both networks contain a few more sites north of $33^{\circ} \mathrm{N}$ in the Southeast United States, we exclude them from analysis because drought conditions are not significant there (cf. Fig. 1a). There are a total of 114 sites providing $\mathrm{PM}_{2.5}$ mass concentrations within the study region (25 sites from IMPROVE and 89 from EPA), including 41 sites with speciation measurements ( 25 sites from IMPROVE and 16 from EPA). 
TABLE 1. GEOS-Chem emissions of dust, wildfires, and biogenic VOCs over the southern United States in June 2010 and June 2011.

\begin{tabular}{|c|c|c|c|c|}
\hline \multirow[b]{2}{*}{ Emission sources } & \multirow[b]{2}{*}{ Species } & \multicolumn{3}{|c|}{ Emission (kt) } \\
\hline & & June 2010 & June 2011 & Difference (\%) \\
\hline Dust & Dust $<2.4 \mu \mathrm{m}$ & 125.6 & 184.01 & +46.5 \\
\hline \multirow[t]{6}{*}{ Wildfire } & $\mathrm{CO}$ & 58.6 & 1163.48 & +1885 \\
\hline & $\mathrm{SO}_{2}$ & 0.68 & 14.1 & +1974 \\
\hline & $\mathrm{NO}_{x}$ & 0.81 & 16.06 & +1883 \\
\hline & $\mathrm{NH}_{3}$ & 0.77 & 15.17 & +1870 \\
\hline & $\mathrm{BC}$ & 0.32 & 6.32 & +1875 \\
\hline & $\mathrm{OC}$ & 2.43 & 57.9 & +2283 \\
\hline \multirow[t]{3}{*}{ Biogenic VOCs } & Total & 3770.54 & 4204.13 & +11.5 \\
\hline & Isoprene & 2606.63 & 2956.74 & +13.4 \\
\hline & Monoterpenes & 453.4 & 481.33 & +6.2 \\
\hline
\end{tabular}

\section{b. GEOS-Chem model}

GEOS-Chem is a global 3D CTM (http://geos-chem. org; version 9-01-03) driven by the NASA Global Earth Observing System (GEOS-5) meteorology field. In the study, we conducted nested-grid simulation (Wang et al. 2004; Chen et al. 2009) over North America $\left(10^{\circ}-70^{\circ} \mathrm{N}\right.$, $140^{\circ}-40^{\circ} \mathrm{W}$ ) at a $0.5^{\circ}$ (latitude) $\times 0.667^{\circ}$ (longitude) horizontal resolution and 47 vertical levels. The lowest model layer is centered at approximately $50 \mathrm{~m}$ above land surface. The chemical boundary conditions were provided by the $4^{\circ} \times 5^{\circ}$ coarse resolution global simulation. GEOSChem follows a coupled tropospheric ozone- $\mathrm{NO}_{x}-\mathrm{VOC}-$ aerosol chemistry (Bey et al. 2001; Park et al. 2004). Secondary organic aerosols (SOA) produced from isoprene, terrenes, and aromatic hydrocarbons are simulated in the model separately as lumped SOA groups (Liao et al. 2007). Gas-aerosol-phase partitioning is performed by the ISORROPIA II thermodynamic equilibrium model (Fountoukis and Nenes 2007). Simulation of mineral dust is implemented by the dust entrainment and deposition (DEAD) mobilization scheme described by Fairlie et al. (2007). Seasonally devegetated regions are considered in the DEAD scheme when calculating the fractional area of land suitable for dust mobilization. The dry deposition process adopts the resistance-in-series scheme (Wesely 1989). Wet scavenging of $\mathrm{PM}_{2.5}$ is based on the scheme described by Liu et al. (2001).

Anthropogenic emissions including sulfur, ammonia, and $\mathrm{NO}_{x}$ over the United States are taken from the EPA National Emissions Inventory (NEI) for 2005 (http:// www.epa.gov/ttn/chief/net/2005inventory.html) with annual-scale factors to obtain the emission inventory for the year 2010, as implemented by van Donkelaar et al. (2008). Primary emissions of OC and EC are provided by Cooke et al. (1999). Biomass burning emissions are from the Global Fire Emissions Database version 3 (GFED v3) with 3-h variability that is based on satellite surface reflectance imagery (Mu et al. 2011; Giglio et al. 2010).
No injection height information is used in the model, and all biomass burning emissions are placed at the surface. Biogenic VOCs emissions are updated every three hours using the Model of Emissions of Gases and Aerosols from Nature (MEGAN) inventory. BVOCs including isoprene, terpenes, and methylbutenol species are calculated as a function of temperature, solar radiation, and leaf area index (LAI) from the meteorology fields or MODIS products (Guenther et al. 2006).

\section{c. Simulated emissions changes during drought}

The model assumes no change in anthropogenic emissions from June 2010 to June 2011. Natural emissions including dust, wildfires, and BVOCs exhibited large enhancements under drought conditions, as summarized in Table 1.

Dust sources within the domain were mainly located in Arizona and from sparsely distributed deserts in New Mexico. Dust particles with diameters less than $2.5 \mu \mathrm{m}$ (size bin of $0.7,1.4$, and 2.5, respectively) are summed up as total dust emissions of relevance to $\mathrm{PM}_{2.5}$ air quality. Monthly-mean dust emissions increased by $46.5 \%$ from 125.6 kilotons $\left(\mathrm{kt} ; 1 \mathrm{kt}=10^{6} \mathrm{~g}\right)$ in June 2010 to $184.0 \mathrm{kt}$ in June 2011, driven partly by nearly doubled $10-\mathrm{m}$ wind speeds over the dust source region (shown in section $2 \mathrm{~b}$ ) and partly by decreased soil moisture. Since the model does not include changes in vegetation between the two months, the model may underestimate dust enhancements in June 2011 by not considering drought-induced reductions in vegetation coverages. Previous studies suggest that the GEOS-Chem model overestimates dust emissions because of uncertainties in dust particle size distribution (PSD) parameterization (Johnson et al. 2012; Ridley et al. 2012). Zhang et al. (2013) implemented an improved dust PSD in the model, which led to a correction in the model of high bias (about a factor of 2-8) in fine clay particles (diameter $<2 \mu \mathrm{m}$ ) compared with surface measurements. This modification is not implemented in the model version used in this 
study and consequently our later analysis indicates a high bias in dust simulation (section 4).

Wildfire emissions of various species from the GFED3 calculation show a large enhancement by a factor of nearly 20 during June of 2011 (Table 1), indicating more fire activities induced by drought. The emission increases were mainly located in Arizona, New Mexico, Texas, and part of the Southeast. Two record-breaking fires-Wallow fire in Arizona (Veraverbeke and Hook 2013) and Las Conchas fire in New Mexico (Weinhold 2011)_together with other smaller fires in Texas and Florida, were responsible for the large emissions increase. Fire emissions of EC and OC contributed directly to $\mathrm{PM}_{2.5}$ enhancements. As precursor gases, $\mathrm{SO}_{2}$, $\mathrm{NO}=\mathrm{i}$, and $\mathrm{NH}_{3}$ emissions from wildfires resulted in increased formation of secondary inorganic aerosols. Long-term variations of fire emissions from GFED3 data indicated that fire emissions in June 2010 were within $30 \%$ of the long-term median emissions between 1997 and 2011, while the June 2011 emissions were 11 times larger, reflecting the impact of severe drought on fire activity.

Total BVOCs emissions from MEGAN show a domain-mean increase of $12 \%$ during the drought, with isoprene increasing by $13.4 \%$ and monoterpenes by $6.2 \%$. The relative increase of BVOCs was $14 \%$ over the Southeast region while the largest increase was $50 \%$ over central and eastern Texas owing to the largest temperature increase. The spatial pattern of increasing BVOCs emissions was consistent with that of temperature increases, as temperature is the key driver in the model of BVOCs emissions. Because the MEGAN inventory implemented in the GEOS-Chem model does not consider the effects of heat stress or reduced soil moisture on BVOCs emissions, the model probably overestimated BVOCs emissions during the drought. In the version of GEOS-Chem model adopted here, the MODIS LAI datasets are updated only up to 2008; thus, LAI in June 2010 and June 2011 are both prescribed with the June 2008 value. According to the MODIS LAI products, average LAI over the Southeast United States decreased by only $2.2 \%$ (from 2.76 in June 2010 to 2.70 in June 2011). By comparison, the LAI decrease over the Southwest United States was $18.5 \%$, from 0.81 to 0.66 , owing to the combined effects of water and heat stress as well as wildfires. Parts of Texas with severe drought conditions showed a LAI decrease of more than $30 \%$. Nevertheless, given the dominant role of the Southeast United States on total BVOCs emissions in the study domain, the exclusion of droughtinduced LAI changes were not expected to result in a significant overestimation of BVOCs emissions during the drought. Additional uncertainties in
BVOCs emissions came from those in vegetation types and soil conditions; the response of these parameters to drought conditions requires independent validation.

\section{Observed and simulated changes in $\mathbf{P M}_{2.5}$ during drought}

In this section, we present analysis on the changes of surface $\mathrm{PM}_{2.5}$ and speciated components based on surface observations along with assessment of the GEOS-Chem model to simulate the observed changes. Observations at the surface sites are averaged onto model grid squares $\left(0.5^{\circ} \times 0.667^{\circ}\right)$ and compared with collocated model results. The $\mathrm{PM}_{2.5}$ changes during the drought herein denote the differences of concentrations in June 2011 and those in June 2010. The Welch two-sample $t$ test (Welch 1938) is conducted to examine if the changes are statistically significant at a $95 \%$ confidence interval $(p<0.05)$. Section $4 \mathrm{a}$ is focused on the changes of total mass concentrations of $\mathrm{PM}_{2.5}$ in terms of regional mean and spatial distribution. Section $4 \mathrm{~b}$ presents analysis on the changes of individual $\mathrm{PM}_{2.5}$ species in order to determine the major contributors to the overall changes.

\section{a. Changes in total $P M_{2.5}$}

The spatial distributions of observed and simulated changes of $\mathrm{PM}_{2.5}$ during the drought are presented in Fig. 3. The SUS domain-mean $\mathrm{PM}_{2.5}$ averaged from the surface observations was $8.8 \mu \mathrm{g} \mathrm{m}^{-3}$ in June 2010, increasing to $11.1 \mu \mathrm{g} \mathrm{m}^{-3}$ in June 2011, which is a relative enhancement of $26.2 \%\left(p<10^{-4}\right)$. The observations show increasing $\mathrm{PM}_{2.5}$ over most of the regions under drought (Fig. 3a). Over New Mexico, monthly-mean $\mathrm{PM}_{2.5}$ increased by more than $60 \%$ during the drought and the highest enhancement observed was $14.5 \mu \mathrm{g} \mathrm{m}^{-3}$ at the southern border of New Mexico. Over Oklahoma and the eastern SUS, including Louisiana, southern Mississippi, Alabama, Georgia, and northern Florida, the mean increase was $27 \%$ or $3.2 \mu \mathrm{g} \mathrm{m}^{-3}$ with the largest enhancement of $17.1 \mu \mathrm{g} \mathrm{m}^{-3}$ over the east coast of Georgia. Among $114 \mathrm{PM}_{2.5}$ sites within SUS, 97 sites (85\%) exhibited certain degrees of $\mathrm{PM}_{2.5}$ enhancements. The majority of the remaining 17 sites showing $\mathrm{PM}_{2.5}$ decreases were located in central and eastern Texas with the largest decrease being $2.65 \mu \mathrm{g} \mathrm{m}^{-3}(24.4 \%)$ at a site in San Antonio, Texas (TX). A separate subdomain is therefore defined over central and eastern TX $\left(27^{\circ}-35^{\circ} \mathrm{N}\right.$, $103^{\circ}-95^{\circ} \mathrm{W}$; Fig. $3 \mathrm{a}$ ) for further analysis of the contrasting response of $\mathrm{PM}_{2.5}$ to drought between TX and the SUS domain at large. There are 12 surface sites in the TX domain and the mean change of surface $\mathrm{PM}_{2.5}$ was a $10.7 \%$ 

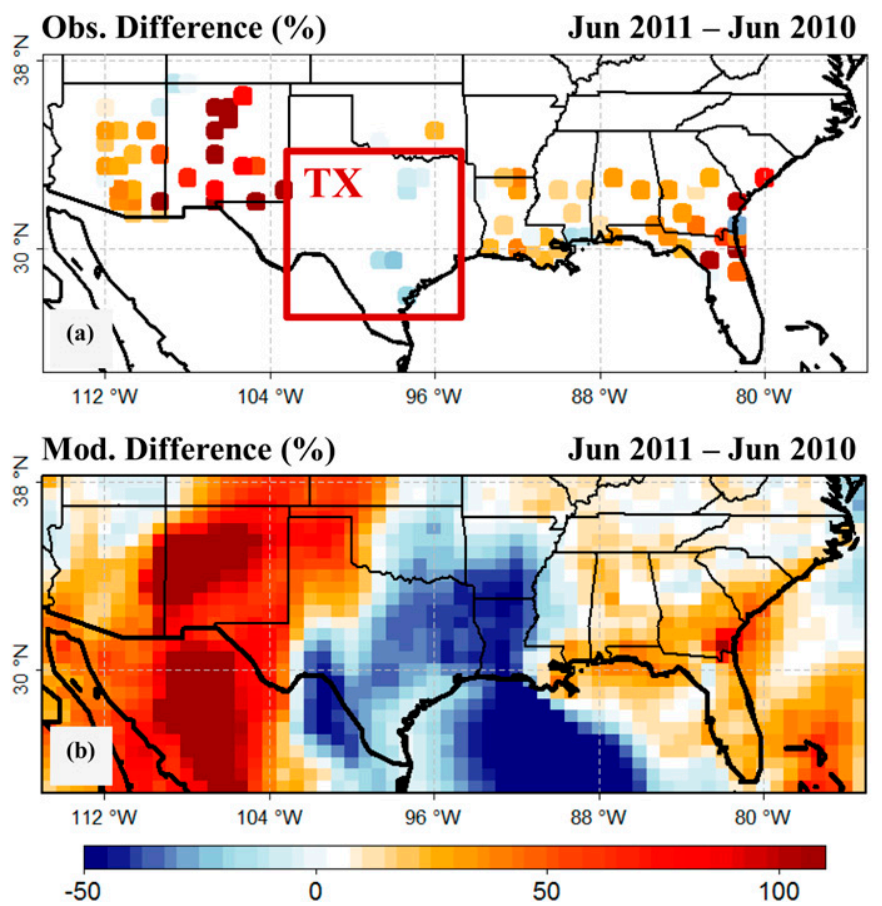

Percent change of total $\mathbf{P M}_{2.5}$

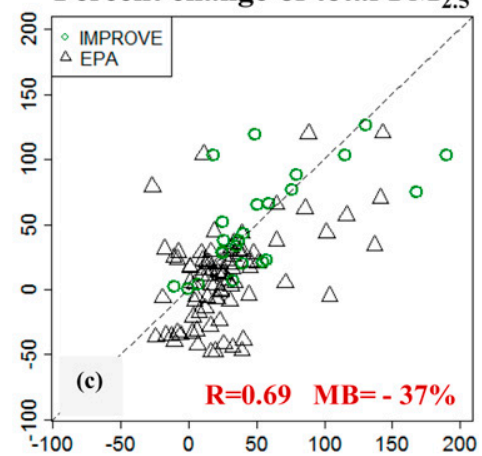

FIG. 3. Percentage changes of monthly-mean ground-level $\mathrm{PM}_{2.5}$ between June 2011 and June 2010 from (a) observations at IMPROVE and EPA surface sites and (b) GEOS-Chem model simulations. (c) The scatterplot of the observed and simulated differences at the surface site locations. The correlation coefficient $(R)$ and mean bias (MB) between model and observations are shown in (c). The red rectangle in (a) denotes the Texas domain (TX).

decrease $\left(-1.16 \mu \mathrm{g} \mathrm{m}^{-3}\right)$. The $p$ value of the mean decrease was 0.12 - not significant at a $95 \%$ confidence interval. A single site near Austin showed an increase larger than $2 \mu \mathrm{g} \mathrm{m}^{-3}$ during the drought, in contrast to decreases observed at surrounding sites. If that site is excluded, the mean $\mathrm{PM}_{2.5}$ decrease over TX was $13.3 \%$ and statistically significant at a $95 \%$ confidence interval $(p=0.05)$.

Figure $3 \mathrm{~b}$ displays the simulated changes of total $\mathrm{PM}_{2.5}$ between June 2010 and June 2011. Simulated mean $\mathrm{PM}_{2.5}$ at collocated grids with the surface sites was $7.5 \mu \mathrm{g} \mathrm{m}^{-3}$ in June 2010 and $8.9 \mu \mathrm{g} \mathrm{m}^{-3}$ in June 2011each about $20 \%$ lower than the observed values. Despite the low bias in absolute concentrations, the model correctly reproduces the observed spatial pattern of a large increase of $\mathrm{PM}_{2.5}$ over the western and eastern SUS in contrast to a significant decrease over TX. The simulated relative change of $\mathrm{PM}_{2.5}$ is $+19 \%$ over SUS and $-28.8 \%$ over TX. As shown in Fig. 3c, the correlation between simulated and observed percentage changes in $\mathrm{PM}_{2.5}$ is 0.69 with a mean bias of $-37 \%$. The negative bias is caused in part by the model discrepancy over Louisiana, Oklahoma, and southern Arkansas. The model shows a reduction of $20 \%-50 \%$ over these states, in contrast to a $\sim 10 \%$ increase in the observations. The model also tends to underestimate the observed magnitude of $\mathrm{PM}_{2.5}$ enhancements over parts of SUS and overestimate $\mathrm{PM}_{2.5}$ decreases over TX. Different biases in $\mathrm{PM}_{2.5}$ species are investigated below for a better understanding of the discrepancy between observed and simulated changes in total $\mathrm{PM}_{2.5}$.

\section{b. Changes in $P M_{2.5}$ components}

Speciated $\mathrm{PM}_{2.5}$ concentrations are analyzed to identify the drought's impact on each chemical component. Given the opposite sign of $\mathrm{PM}_{2.5}$ changes between TX and SUS, the two regions are analyzed separately. There are 41 speciated sites over SUS (including 5 sites in TX), compared to a total of 73 nonspeciated sites providing mass concentrations of total $\mathrm{PM}_{2.5}$. Regional-mean statistics of observed and simulated monthly-mean concentrations of $\mathrm{PM}_{2.5}$ species are summarized in Table 2 and graphically displayed in Fig. 4. Over SUS (Fig. 4a), speciated observations showed that sulfate and OC each contributed to $\sim 30 \%$ of total $\mathrm{PM}_{2.5}$ in June 2010 , with dust taking up $22 \%$. Total $\mathrm{PM}_{2.5}$ from the 41 speciated sites showed an increase of $47.4 \%$, consistent in sign but larger than the $26.2 \%$ increase presented in section $4 \mathrm{~b}$, which was derived from the combination of speciated and nonspeciated sites. This difference relates to different spatial representation between sparsely distributed speciated and nonspeciated sites; there was a relatively 
TABLE 2. Surface $\mathrm{PM}_{2.5}$ and its speciation concentrations $\left(\mu \mathrm{g} \mathrm{m}^{-3}\right)$ from observations and GEOS-Chem model simulation over SUS and TX regions in June 2010 and June 2011.

\begin{tabular}{|c|c|c|c|c|c|c|c|}
\hline \multirow[b]{3}{*}{ Region } & \multirow[b]{3}{*}{ Species } & \multicolumn{3}{|c|}{ Observation } & \multicolumn{3}{|c|}{ Model } \\
\hline & & \multicolumn{2}{|c|}{ Mean (std dev) } & \multirow{2}{*}{$\frac{\text { Difference }}{\text { June } 2011 \text { - June } 2010}$} & \multicolumn{2}{|c|}{ Mean (std dev) } & \multirow{2}{*}{$\begin{array}{c}\text { Difference } \\
\text { June } 2011 \text { - June } 2010\end{array}$} \\
\hline & & June 2010 & June 2011 & & June 2010 & June 2011 & \\
\hline \multirow[t]{9}{*}{ SUS } & $\mathrm{PM}_{2.5}$ (all sites) & $8.84(3.43)$ & $11.16(4.06)$ & $2.32(26.2 \%)$ & $7.50(2.71)$ & $8.90(3.1)$ & $1.40(18.7 \%)$ \\
\hline & $\mathrm{PM}_{2.5}$ (speciated sites) & $6.23(2.39)$ & $9.18(2.73)$ & $2.95(47.4 \%)$ & $7.28(2.78)$ & $9.77(3.37)$ & $2.49(34.2 \%)$ \\
\hline & $\mathrm{SO}_{4}^{2-}$ & $1.77(1.19)$ & $1.81(0.96)$ & $0.04(2.3 \%)$ & $1.39(0.73)$ & $1.33(0.58)$ & $-0.06(-4.0 \%)$ \\
\hline & $\mathrm{NH}_{4}^{+}$ & $0.49(0.28)$ & $0.50(0.23)$ & $0.01(4.2 \%)$ & $0.60(0.36)$ & $0.56(0.22)$ & $-0.04(-7.1 \%)$ \\
\hline & $\mathrm{NO}_{3}^{-}$ & $0.23(0.10)$ & $0.27(0.08)$ & $0.04(17.4 \%)$ & $0.38(0.43)$ & $0.30(0.28)$ & $-0.08(-22.5 \%)$ \\
\hline & EC & $0.26(0.20)$ & $0.41(0.38)$ & $0.15(60.2 \%)$ & $0.20(0.13)$ & $0.33(0.50)$ & $0.13(63.3 \%)$ \\
\hline & $\mathrm{OC}$ & $1.92(1.30)$ & $4.21(5.03)$ & $2.29(118.9 \%)$ & $1.39(0.97)$ & $3.23(2.11)$ & $1.84(132.7 \%)$ \\
\hline & Sea salt & $0.17(0.13)$ & $0.19(0.15)$ & $0.02(9.8 \%)$ & $0.09(0.07)$ & $0.08(0.08)$ & $-0.01(-3.0 \%)$ \\
\hline & Dust & $1.37(1.03)$ & $1.69(1.21)$ & $0.32(23.5 \%)$ & $3.23(2.79)$ & $3.94(3.32)$ & $0.71(22.2 \%)$ \\
\hline \multirow[t]{9}{*}{$\mathrm{TX}$} & $\mathrm{PM}_{2.5}$ (all sites) & $10.82(1.54)$ & $9.66(1.50)$ & $-1.16(-10.7 \%)$ & $7.58(1.23)$ & $5.4(0.69)$ & $-2.18(28.8 \%)$ \\
\hline & $\mathrm{PM}_{2.5}$ (speciated sites) & $8.79(1.79)$ & $8.33(1.61)$ & $-0.46(-5.2 \%)$ & $7.67(1.96)$ & $5.51(0.64)$ & $-2.16(-28.2 \%)$ \\
\hline & $\mathrm{SO}_{4}^{2-}$ & $3.33(0.74)$ & $2.46(0.38)$ & $-0.87(-26.1 \%)$ & $1.90(0.37)$ & $1.48(0.26)$ & $-0.42(-22.3 \%)$ \\
\hline & $\mathrm{NH}_{4}^{+}$ & $0.78(0.13)$ & $0.58(0.15)$ & $-0.20(-25.0 \%)$ & $0.88(0.27)$ & $0.56(0.11)$ & $-0.32(-36.90 \%)$ \\
\hline & $\mathrm{NO}_{3}^{-}$ & $0.33(0.12)$ & $0.38(0.04)$ & $0.05(14.1 \%)$ & $0.76(0.47)$ & $0.20(0.15)$ & $-0.56(-74.00 \%)$ \\
\hline & $\mathrm{EC}$ & $0.33(0.13)$ & $0.33(0.13)$ & $0.00(0.9 \%)$ & $0.20(0.07)$ & $0.16(0.05)$ & $-0.04(-18.80 \%)$ \\
\hline & $\mathrm{OC}$ & $2.24(0.87)$ & $2.87(0.65)$ & $0.63(28.6 \%)$ & $1.63(0.73)$ & $1.78(0.52)$ & $0.15(9 \%)$ \\
\hline & Sea salt & $0.30(0.28)$ & $0.41(0.29)$ & $0.11(35.7 \%)$ & $0.20(0.15)$ & $0.20(0.14)$ & $0(2.8 \%)$ \\
\hline & Dust & $1.40(0.54)$ & $1.33(0.19)$ & $-0.13(-5.1 \%)$ & $2.10(1.26)$ & $1.13(0.14)$ & $-0.97(-45.90 \%)$ \\
\hline
\end{tabular}

larger weight of speciated sites in New Mexico and Arizona where $\mathrm{PM}_{2.5}$ had the largest increase. Averaging over the SUS domain, most of the $\mathrm{PM}_{2.5}$ species showed higher concentrations during the drought, except for sulfate, which presented minor change. OC increased from $1.92 \mu \mathrm{g} \mathrm{m}^{-3}$ in June 2010 to $4.21 \mu \mathrm{g} \mathrm{m}^{-3}$ in June 2011, which was a relative increase of $119 \%(p<0.01)$ and accounted for $78 \%$ of total $\mathrm{PM}_{2.5}$ enhancements during the drought. Dust and EC increased by $0.32 \mu \mathrm{g} \mathrm{m}^{-3}$ $(23.5 \% ; p<0.2)$ and $0.15 \mu \mathrm{g} \mathrm{m}^{-3}(60.2 \% ; p<0.02)$, respectively. There was an increase of $17 \%$ in nitrate $(p<$ $0.05)$ and an increase of $10 \%$ in sea salt species $(p=0.7)$. The model reproduced the observed sulfate and OC concentrations within $\sim 25 \%$ yet overestimated dust by $\sim 130 \%$ for both months mainly because of the high bias in dust emissions discussed in section 3c. On the other hand, measured dust concentrations were subject to observation uncertainty, which was estimated to exceed $16 \%$ owing to ions' adhesion on filters and estimation of total mass from fixed combination of metal species (Flanagan et al. 2006). The simulated relative changes of OC, EC, sulfate, and dust were $133 \%$, $63.3 \%,-4.0 \%$, and $22.2 \%$, respectively, consistent with the observed relative changes of $119 \%, 60.2 \%$, $2.3 \%$, and $23.5 \%$. The model correctly predicted that the large enhancement in carbonaceous aerosols, (a)

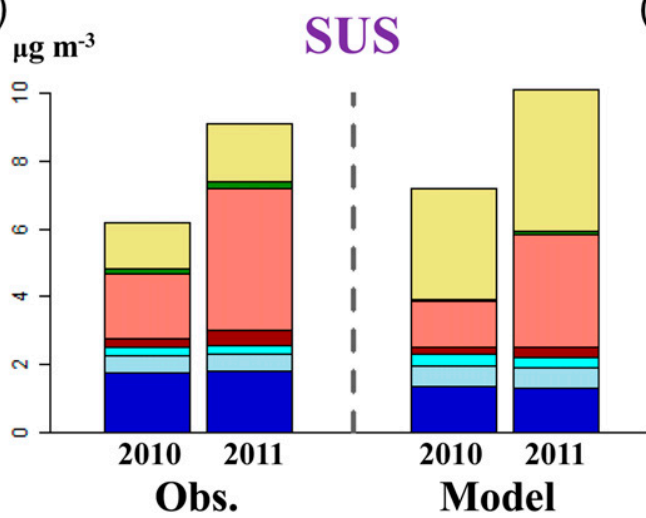

(b)

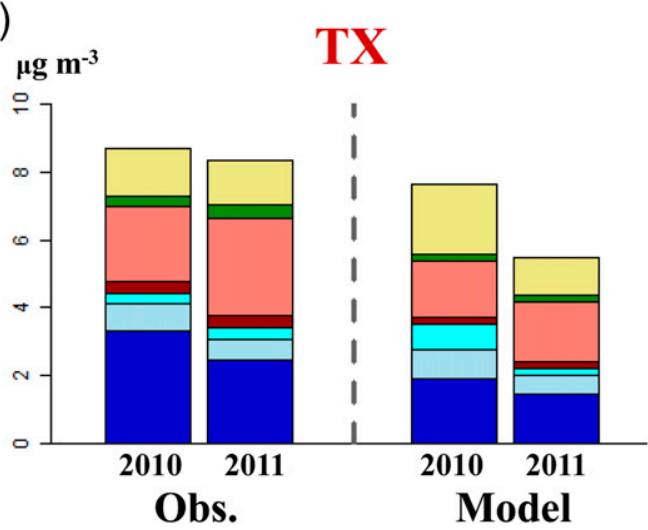

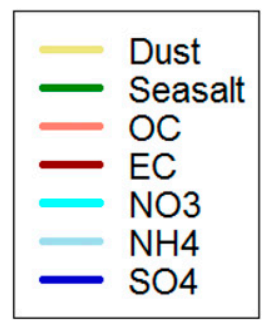

FIG. 4. Observed and GEOS-Chem simulated monthly-mean $\mathrm{PM}_{2.5}$ by species averaged over the surface site locations in the (a) SUS and (b) TX domains during June 2010 and June 2011. 
particularly OC, was the key driver of increasing $\mathrm{PM}_{2.5}$ over SUS during the drought.

The largest inconsistency between model and observations was with nitrate. The model simulated a large decrease in nitrate $(22.5 \%)$ for the drought month, whereas observations showed an increase of $17.4 \%$. This inconsistency was caused by the model overestimate of observed nitrate concentrations in June 2010 under the normal conditions (Table 2). The discrepancy in nitrate was especially large over Oklahoma and Louisiana and was a major factor in causing the model to predict a decrease in total $\mathrm{PM}_{2.5}$ over this region-in contrast to an increase in observations. The inconsistency in nitrate is attributable to model deficiencies as well as uncertainty in nitrate observations. The high bias in nitrate is a known problem in GEOS-Chem and has been attributed to underestimation of sulfate concentrations, bias in ammonia emissions, excessive production of nitric acid, and deposition process (Park et al. 2004; Heald et al. 2012; Zhang et al. 2012; Evans and Jacob 2005). On the other hand, nitrate reevaporation on Teflon filters is a known issue for the measurements with the estimated uncertainty of $\sim 10 \%-28 \%$ (Hering and Cass 1999; Hyslop 2008). Given the model problems with nitrate and the minor role of nitrate in the overall $\mathrm{PM}_{2.5}$ changes during the drought, we did not use the model to analyze nitrate changes in this study. The model predicted a decrease in sulfate, ammonium, and sea salt over SUS that was inconsistent with observations, but again these species had much smaller contributions to the overall $\mathrm{PM}_{2.5}$ changes over SUS than carbonaceous aerosols. To summarize, the lack of nitrate increase, combined with the underestimate of OC absolute enhancement due to smaller concentrations predicted for each year, explains model underestimation of the overall $\mathrm{PM}_{2.5}$ enhancements over SUS during the drought presented before.

Over TX (Fig. 4b), observations show that sulfate contributed $38 \%$ of total $\mathrm{PM}_{2.5}$ mass in June 2010, with OC and dust contributing $\sim 20 \%$ each. Most of the $\mathrm{PM}_{2.5}$ components showed a decrease during the drought except for a $0.63 \mu \mathrm{g} \mathrm{m}^{-3}$ increase in OC $(29 \% ; p=0.23)$. Sulfate decreased by $0.87 \mu \mathrm{g} \mathrm{m}^{-3}(-26 \% ; p<0.05)$, which offset the OC increase and was the main driver for the overall $\mathrm{PM}_{2.5}$ decrease over this region during the drought. The model underestimated most of the species by $\sim 30 \%$, yet it reproduced the observed magnitude of sulfate decrease during the drought. The model predicted a $9 \%$ increase in OC, which was consistent with the observations in terms of the direction of change but lower in magnitude. Compared with the observed $25 \%$ decrease in ammonium, the model simulated a $37 \%$ decrease. The simulated decrease of dust and increase of sea salt were consistent with observed changes in sign but differed in magnitude. Observed and simulated nitrate changes were opposite in sign over TX because of the same reasons discussed above. However, the model was consistent with observations in attributing sulfate change as the key driver for $\mathrm{PM}_{2.5}$ decrease during the drought.

To summarize, both observations and model simulations show that sulfate, OC, and dust were major components that all together contribute to $>80 \%$ mass of $\mathrm{PM}_{2.5}$ over SUS and TX during both the normal and the drought month. The changes of total $\mathrm{PM}_{2.5}$ during the drought were largely determined by the change of these major components. For OC and sulfate with complex chemistry processes that depend on meteorology conditions, we separately examine the drought's impacts on them in the following two sections.

\section{Impacts of drought on $\mathrm{OC}$}

The effects of drought on OC through wildfire and BVOCs emissions are discussed in section 3c. In this section, we first examine the spatial distribution of drought-induced changes of OC concentrations. A budget analysis will be followed, focusing on the drought's impact on chemistry, transport, and deposition processes of OC.

\section{a. Spatial change}

Observed and simulated OC concentrations for June 2010, 2011, and the percentage differences are displayed in Fig. 5. During the normal month of June 2010, OC concentrations increased from west to east, driven by the west-to-east gradient in forest coverage and human activities that contribute to both primary and secondary OC sources. Observations show that during the drought month, mean OC concentrations increased by a factor of 3 in New Mexico (from 0.98 to $3.99 \mu \mathrm{g} \mathrm{m}^{-3}$ ) and by $50 \%$ in the Southeast (from 3.52 to $5.37 \mu \mathrm{g} \mathrm{m}^{-3}$ ). The model successfully captured the spatial heterogeneity of OC during both the normal and drought months, showing the spatial correlations, with observations being 0.86 and 0.73 , respectively. The model underestimated OC concentrations by $26 \%$ for June 2010 and by $6.4 \%$ for June 2011. Over the eastern and western parts of the SUS domain, the OC underestimation was less drastic at the IMPROVE sites $(\sim-10 \%)$ than at the EPA sites $(\sim-38 \%)$, suggesting the possible influence of urban or residential pollutions on the EPA sites not captured by the model's coarse grid. The model performed better in simulating the relative changes of OC from June 2010 to June 2011. The model predicted a threefold increase in OC over western SUS as well as a smaller increase over the eastern SUS, both within $2 \%$ of the observed 

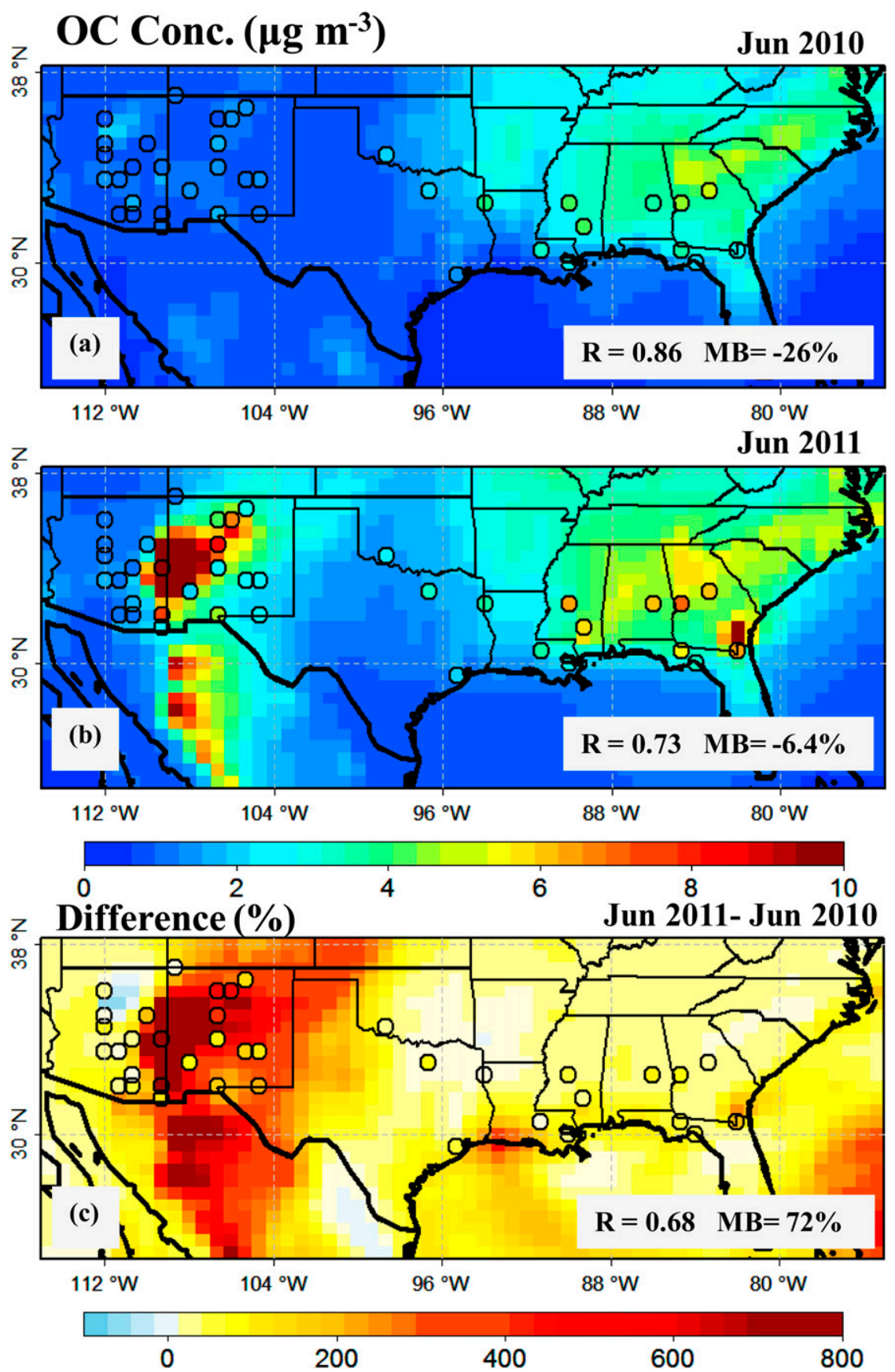

FIG. 5. GEOS-Chem simulated monthly-mean OC concentrations at the surface for (a) June 2010, (b) June 2011, and (c) the differences. Observed values at the surface sites are shown as colored circles. The correlation coefficient $(R)$ and mean bias (MB) between model and observations are shown in each panel.

changes. Overall, the model captured the major change patterns during the drought $(R=0.68)$. This indicates that the model has the ability to simulate the major mechanisms that affect the atmospheric OC contents under different conditions and lends confidence to the budget analysis presented below.

\section{b. Budget analysis and major drought impacts}

Budget analysis of OC within the PBL was performed for the SUS domain (including TX). OC sources include direct emissions, chemical production, and inflow, while sink terms include dry and wet deposition as well as 
outflow from the domain. The mean afternoon PBL for the region was at the twelfth model layer $(\sim 1.6 \mathrm{~km}$ above surface) for June 2010 and increased to the fourteenth model layer $(1.9 \mathrm{~km})$ under drought conditions. For comparative purposes, we included all the lowest 14 layers for budget calculation for both months. Table 3 compares the budget terms of OC between the normal and drought month. Fluxes were calculated at the boundaries and summed up as the domainwide inflow or outflow in the budget. During normal conditions in June 2010, the monthly-mean atmospheric burden of OC was $0.82 \mathrm{kt} \mathrm{C}$ within the afternoon PBL. Direct emissions of OC included $2.6 \mathrm{ktC}$ from biomass burning and $5.7 \mathrm{kt} \mathrm{C}$ from other sources, including anthropogenic emissions. SOA formation from BVOCs contributed to a total source of $3.6 \mathrm{ktC}$, and the inflow from surrounding regions brought an additional $5.9 \mathrm{kt} \mathrm{C}$ of OC. Wet and dry deposition was 1.6 and $4.1 \mathrm{ktC}$, respectively. Outflow represented a sink of $11.9 \mathrm{kt} \mathrm{C}$. In sum, total OC sources over SUS were $17.8 \mathrm{kt} \mathrm{C}$ in June 2010, while total sink was $17.6 \mathrm{kt} \mathrm{C}$, presenting a $0.2 \mathrm{kt} \mathrm{C}$ net gain for the month.

During the drought month, the OC contents within the PBL increased by more than fourfold compared with the normal month. This is more than double the relative increase at the surface, indicating larger impacts of drought on $\mathrm{OC}$ above the surface. Direct emissions of OC increased by $58 \mathrm{kt} \mathrm{C}$ (almost a factor of 7) within the domain, mainly attributed to enhanced wildfire emissions discussed in section 3 . Since the model assumed all fire emissions from the surface layer, the larger enhancement of OC in the PBL than at the surface was primarily caused by model transport. Figure 6a displays the spatial distribution of increased OC emissions from biomass burning. The large increase of fire emissions in New Mexico, central Texas, and south Georgia corresponded well with the hot spots of surface OC enhancements during the drought. Within east Arizona and New Mexico, the Wallow fire $\left(33.8^{\circ} \mathrm{N}, 109^{\circ} \mathrm{W}\right)$ and the Las Conchas fire $\left(35.4^{\circ} \mathrm{N}\right.$, $\left.104.2^{\circ} \mathrm{W}\right)$ contributed to more than 100 times enhancements of OC emissions at the fire locations. Satellite images show that the dense smokes from the fires were extended $150 \mathrm{~km}$ horizontally and elevated to as high as $15-\mathrm{km}$ altitude because of atmospheric instability (Ruminski et al. 2011). An increase in wind speeds during the drought also promoted the duration and spatial impact of wildfires.

In addition to direct emissions, production of SOA increased by $31 \%$ under drought conditions. Figure $6 \mathrm{~b}$ presents the simulated spatial distribution of SOA production changes within the PBL. SOA production was $100 \%$ higher over New Mexico and $\sim 60 \%$ higher over the Southeast. The net production of SOA depends on
TABLE 3. GEOS-Chem simulated budget of OC over SUS for June 2010 and June 2011. Units are kt C (kt C month ${ }^{-1}$ for fluxes).

\begin{tabular}{lcc}
\hline \multicolumn{1}{c}{ SUS } & June 2010 & June 2011 \\
\hline Atmospheric content & 0.82 & 3.48 \\
Source & 17.8 & 85.5 \\
Emission & 8.3 & 66.3 \\
$\quad$ Biomass burning & 2.6 & 60.3 \\
Others & 5.7 & 6.0 \\
Chemical production & 3.6 & 4.7 \\
Inflow & 5.9 & 14.5 \\
Sink & 17.6 & 82.6 \\
Dry deposition & 1.6 & 7.0 \\
Wet deposition & 4.1 & 6.9 \\
Outflow & 11.9 & 68.7 \\
\hline
\end{tabular}

BVOCs emissions, oxidation process, and partition between the particle and the gas phase. The MEGAN inventory, driven by the model's meteorology, indicated a domain-mean increase of $12 \%$ in total BVOCs emissions and the increase was concentrated over regions with large temperature increases during the drought (section 3c). However, the effect of heat stress and reduced soil moisture on vegetation and BVOCs emissions were not considered here, which will render lower BVOCs emissions during the drought than what suggested by the model. The relative increase of SOA production was more than double the relative increase of BVOCs emissions, which can be partly explained by an increase in particle-phase partition as a result of larger surface areas of aerosols from increasing wildfire emissions. The spatial distribution of SOA production enhancements correlated well with that of wildfires $(R=$ $0.53)$. While the increase of BVOCs emissions was the largest over central and eastern Texas because of higher temperatures, the increase of SOA production was less significant there as higher temperatures also shift the partitioning toward gas phase.

Another important OC source during the drought was net inflow of OC from adjacent regions. During June 2011, the amount of OC transported into the region was $14.5 \mathrm{kt} \mathrm{C}$-almost 2.5 times larger than that during June 2010 - and the main contribution was the increased OC inflow from Mexico. Wang et al. (2006) suggest that smoke transported from southern Mexico during the 1998 and 2003 drought years was responsible for severe air quality degradation over the Southeast United States during late spring and summer because of the prevailing southerly winds. During June 2011, Mexico was in serious drought and wildfires were largely increased over northern and southern Mexico, releasing large amounts of OC that were transported into the United States across the U.S.-Mexico border as well as through the Gulf of Mexico under the prevailing southerly and 

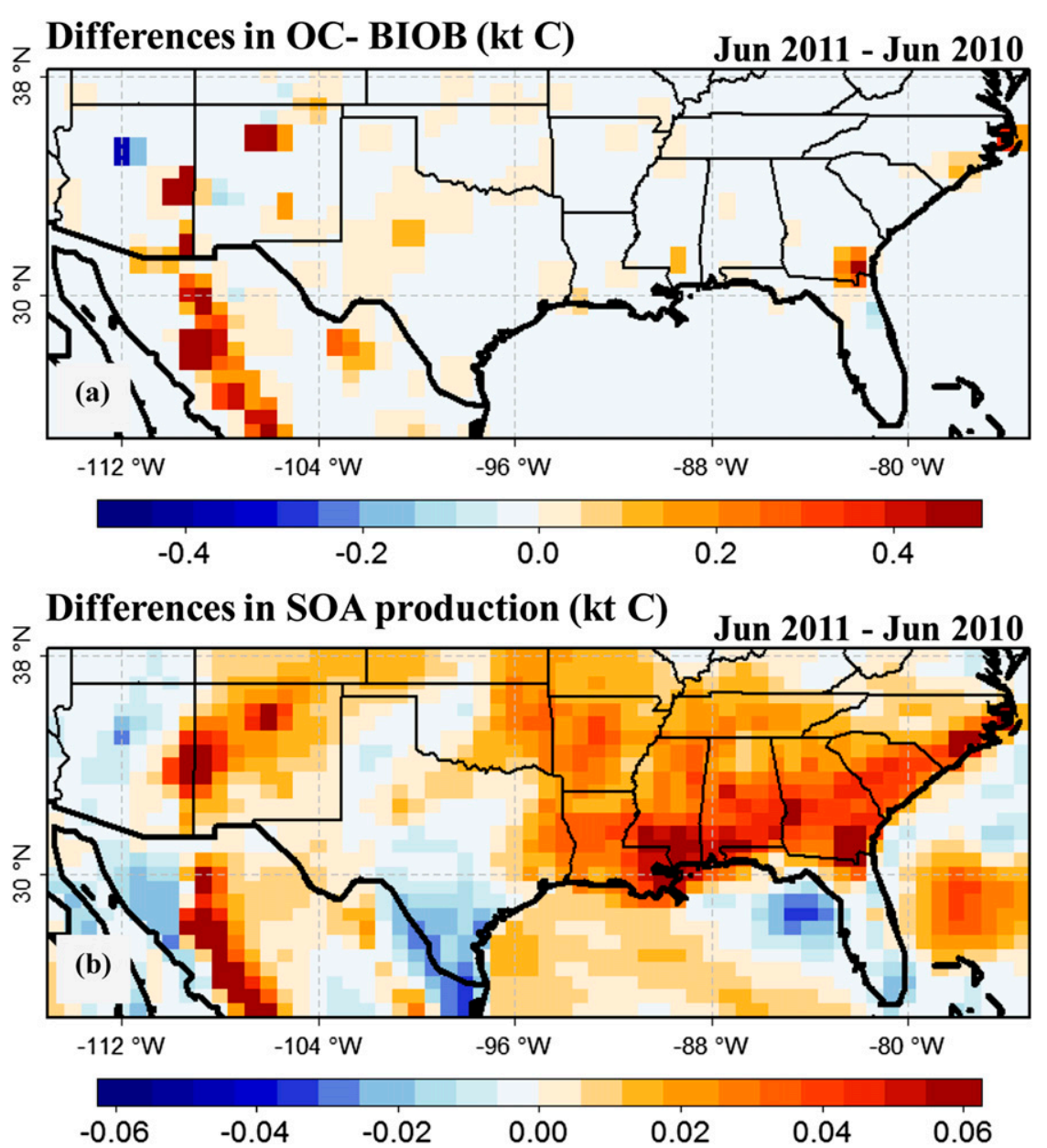

FIG. 6. Differences in (a) direct emissions of OC from biomass burning and (b) SOA production within the PBL from BVOCs between June 2011 and June 2010 (June 2011 values minus June 2010 values).

southeasterly winds. Higher southeast winds during the drought also promoted transport of pollutions from Mexico into the southern United States. As shown in Table 2, total sources of OC were increased by more than a factor of 4 to $\sim 85.5 \mathrm{ktC}$ in the drought month. OC outflow was increased by a factor of 5 during the drought month as a result of increased emissions and OC burden.

Despite a $33 \%$ decrease in rainfall during the drought, wet deposition of OC showed an increase of $68 \%$. The loss of OC through dry deposition was 3 times larger than that during the normal month. The increase in deposition can be attributed to larger emissions and consequently higher atmospheric burdens. The largest increase of OC wet deposition was simulated over the east SUS $(\sim 150 \%$ increase), whereas a decrease of $\sim 10 \%-50 \%$ was found over New Mexico and central Texas with lower precipitation intensity and frequency under normal conditions. Analysis of the simulated day-to-day variations of wet deposition over Southeast United States indicates the coincidence of several large precipitation events with enhanced OC concentrations (Fig. S3 in the supplementary material), which resulted in an increase in wet removal efficiency (i.e., the amount of OC removed per millimeters of precipitation).

From the budget analysis, we conclude that the large increase in wildfire emissions $(+58 \mathrm{kt} \mathrm{C})$, enhanced SOA production $(+1.1 \mathrm{ktC})$, and increased transboundary inflow from Mexico $\left(+8.6 \mathrm{kt} \mathrm{C}\right.$ month $\left.^{-1}\right)$ were the three largest contributors to higher atmospheric OC contents under drought conditions. The drought also impacts dry and wet deposition processes, but their effects on overall OC budget are smaller.

\section{Impact of drought on sulfate}

The decrease of $\mathrm{PM}_{2.5}$ in TX was mainly caused by a $26 \%$ decrease in sulfate, which is a different response to drought compared to OC. In this section, we first 

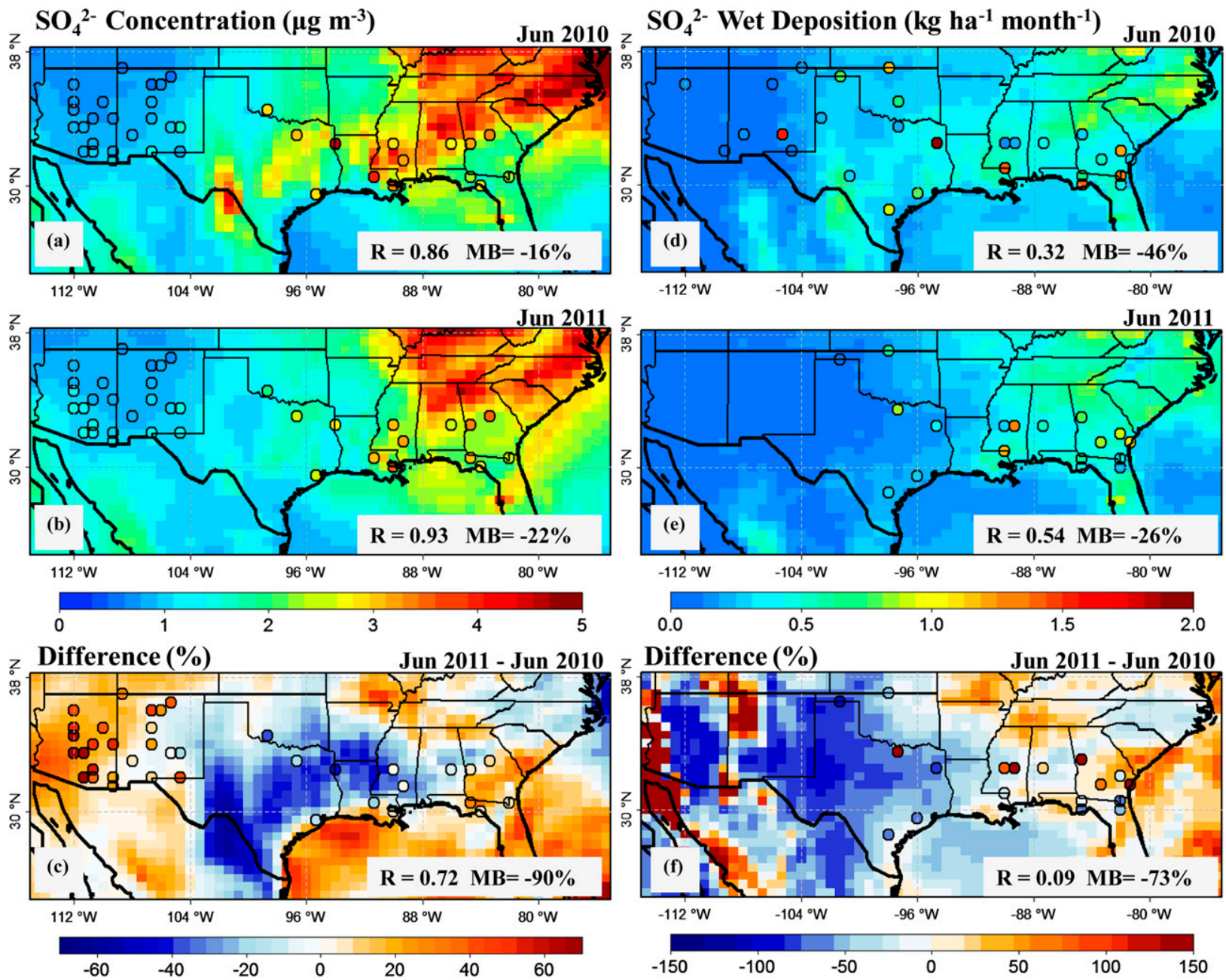

FIG. 7. (left) Simulated monthly-mean sulfate concentrations and (right) wet deposition fluxes at the surface for (a),(d) June 2010 , (b),(e) June 2011, and (c),(f) the differences. Observed values at the surface sites are shown in each figure as colored circles. Concentration observations are obtained from IMRPOVE and EPA, and wet deposition fluxes are from the NADP database. The correlation coefficient $(R)$ and mean bias $(\mathrm{MB})$ between model and observations are shown in each panel.

investigate the spatial distribution of sulfate changes for the SUS domain. Budget analysis of total sulfur will be presented for the TX region to quantify the impact of drought on chemistry, transport, and deposition processes.

\section{a. Spatial change}

Observed and simulated surface sulfate concentrations for June 2010, 2011, and their differences are displayed in Figs. 7a-c. The west-east gradient in sulfate concentrations was well reproduced by the model, corresponding to higher anthropogenic emissions of $\mathrm{SO}_{2}$ in the east. Observations reveal essentially no change (a $2.32 \%$ difference) in the domain-mean sulfate concentrations over SUS between June 2010 and June 2011, owing to the cancellation between positive and negative changes within the large domain. The model had a bias of $-20 \%$ in sulfate concentrations for both months, yet it was consistent with observations in predicting no change over SUS during the drought. The model successfully captured the observed spatial pattern with a correlation $(R)$ of 0.86 and a bias of $-16 \%$ for June 2010 and $R$ of 0.93 and bias of $-22 \%$ for June 2011, respectively. While the IMPROVE sites were located in cleaner regions compared to the EPA sites, simulated sulfate showed a $20 \%-30 \%$ underestimation for both networks, suggesting that the low bias in sulfate was not related to the model's resolution but systematic bias in processes such as emissions and chemical formation. As the focus here is on the change in sulfate during the drought, the low bias in absolute concentrations of each month canceled out and the model successfully reproduced the observed magnitude and spatial gradient in the relative changes of sulfate. As shown in Fig. 7c, the 


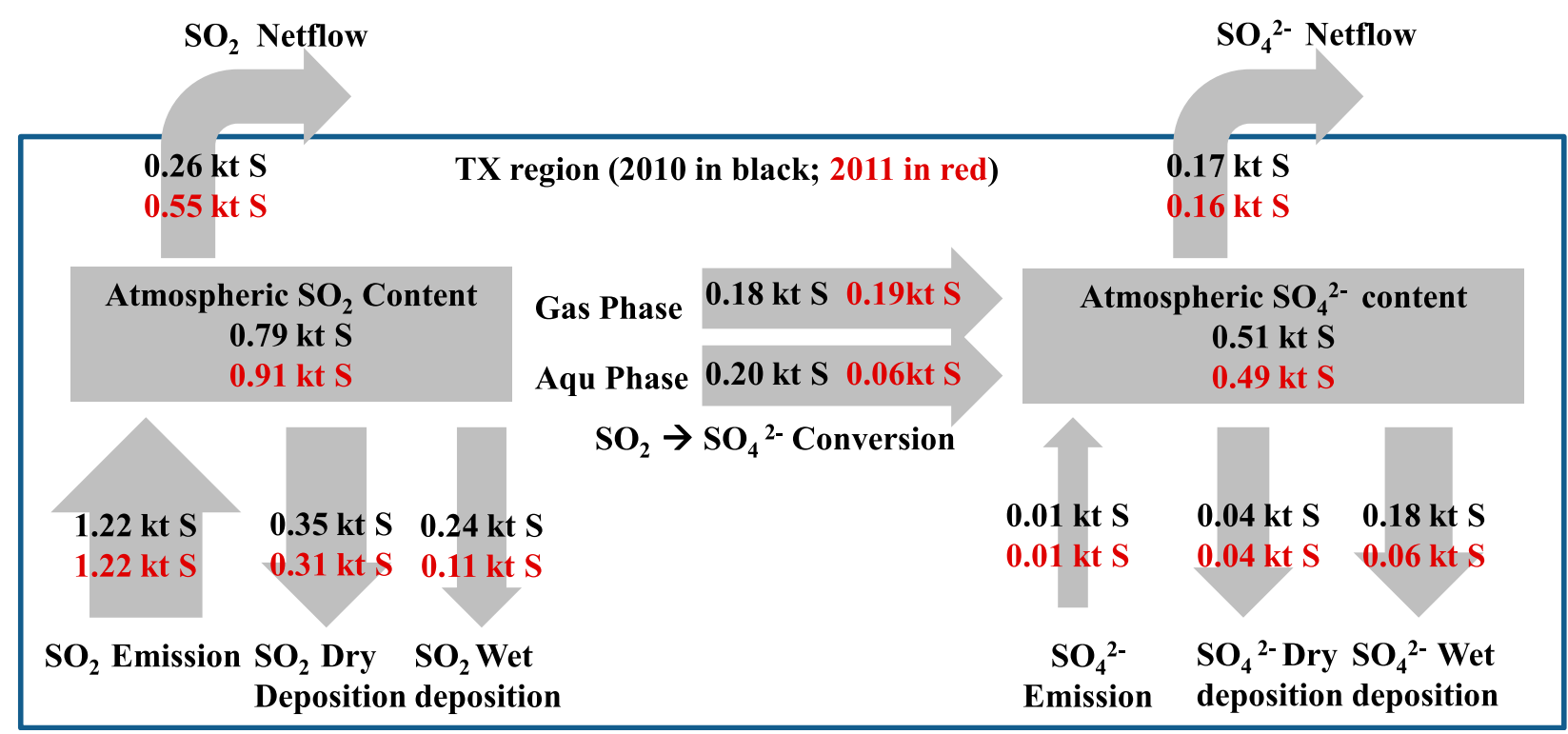

FIG. 8. Schematic of daily budget terms of total sulfur over the TX domain for June 2010 (numbers in black) and June 2011 (numbers in red).

large decrease in sulfate over TX and increase over the western and eastern SUS were captured by the model.

Simulated wet deposition fluxes of sulfate are compared with observations from the National Atmospheric Deposition Program (NADP; https://nadp.isws.illinois. edu/), which have about 30 surface sites in the SUS domain (Figs. 7d-f). While observed wet deposition fluxes exhibited large spatial variations, higher deposition fluxes tend to coincide with higher sulfate concentrations. Monthly total deposition fluxes at the NADP sites were $0.62 \mathrm{~kg} \mathrm{ha}^{-1}$ and $0.60 \mathrm{~kg} \mathrm{ha}^{-1}$ in June 2010 and 2011, respectively, exhibiting a mere $3 \%$ decrease across the SUS region. Within TX, however, sulfate wet deposition fluxes decreased from 0.62 to $0.41 \mathrm{~kg} \mathrm{ha}^{-1}$, which was a relative decrease of $34 \%$ during the drought. The model captured to some extent the observed gradient of wet deposition in both months, such as higher deposition in the central and eastern SUS than in the west. The correlation between simulated and observed deposition fluxes was poorer than that of sulfate concentrations: 0.32 for June 2010 and 0.54 for June 2011. The simulated changes showed some consistency with observations in terms of the directions of change, including decreases over TX and increases over east SUS, but the model had poor correlation with the observed magnitude of changes. Within TX, simulated monthly-mean sulfate wet deposition at collocated sites decreased from $0.30 \mathrm{~kg} \mathrm{ha}^{-1}$ in 2010 to $0.14 \mathrm{~kg} \mathrm{ha}^{-1}$ in 2011-a much larger relative decrease (114\%) than observed. The discrepancy in wet deposition fluxes could result from subgrid variability of rainfall that cannot be simulated by the model.

\section{b. Budget analysis for total sulfur}

Since the model reproduces the spatial gradient of sulfate concentrations under both normal and drought conditions and captures the decrease of sulfate and its wet deposition over TX region during the drought month, we used the model to examine the role of different processes that influence sulfate concentrations through budget analysis of total sulfur $\left(\mathrm{SO}_{2}+\mathrm{SO}_{4}\right)$. The budget analysis was conducted for the TX region, which exhibits a unique feature of a large decrease in sulfate during the drought. We included the lowest 14 layers for budget calculation-the same as in the OC analysis. Figure 8 illustrates the daily mean budget terms within the PBL averaged from month-long simulations for June 2010 and 2011, respectively. Sulfur sources include $\mathrm{SO}_{2}$ emissions from anthropogenic activities and biomass burning as well as a small amount of sulfate emitted directly from anthropogenic sources. Sinks of sulfur include dry and wet deposition. For simplification, inflow and outflow were combined and presented as net flux for the region. Besides the source and sink for total sulfur, we also quantified the change in the conversion rate of $\mathrm{SO}_{2}$ to sulfate through gas and aqueous-phase oxidation, although this term does not directly contribute to the total sulfur budget.

During the drought month (June 2011), atmospheric sulfur contents over TX increased by $7.7 \%$, including a $15 \%$ increase in $\mathrm{SO}_{2}$ partly offset by a $4 \%$ decrease in sulfate. The relative decrease of sulfate within the PBL was much smaller than that observed and simulated at 

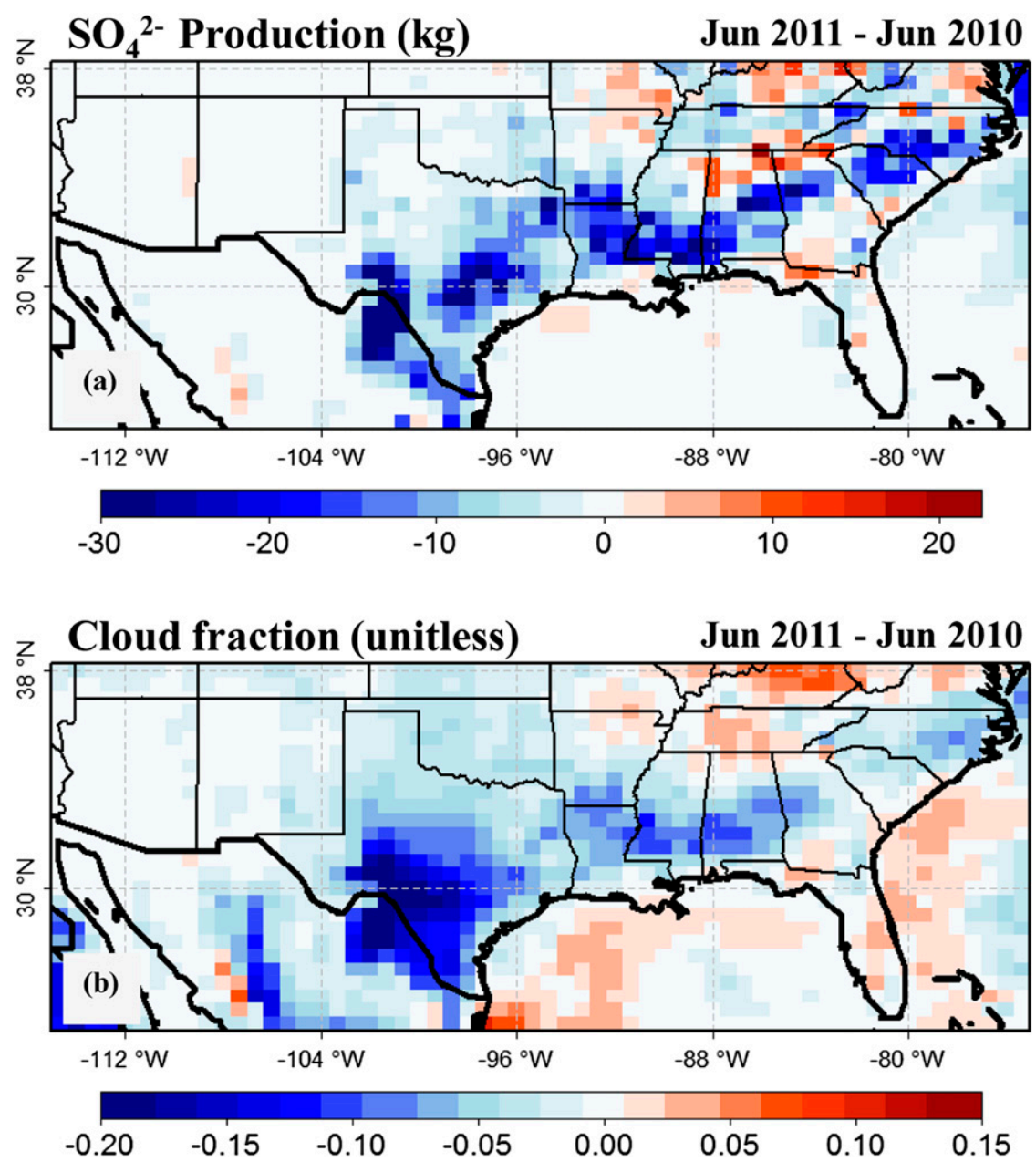

FIG. 9. (a) GEOS-Chem simulated changes in monthly total sulfate production at the surface between June 2011 and June 2010. (b) Changes in low-level (1000-700 hPa) cloud fractions between the same periods from MERRA.

the surface. Total sulfur emissions showed only minor changes compared to 2010 since anthropogenic emissions were held constant from 2010 to 2011. Compared with the normal month, the conversion of $\mathrm{SO}_{2}$ to sulfate was reduced by $34 \%$ within the PBL during the drought, attributable to a $70 \%$ decrease in aqueous-phase oxidation offset partially by a $5 \%$ increase in gas-phase oxidation. The large decrease of aqueous-phase oxidation was the major cause for the increased $\mathrm{SO}_{2}$ burden and consequently decreased sulfate burden during the drought. Figure 9a displays the simulated changes in sulfate production rate at the surface. There was a $78 \%$ decrease in sulfate production over TX at the surface, much larger than the relative reduction within the PBL $(34 \%)$, which explains the smaller relative decrease of sulfate within the PBL than at the surface. Aqueousphase oxidation in 2010 was responsible for nearly $80 \%$ of total sulfate production at the surface, while this fraction dropped to less than $50 \%$ during the drought month; the corresponding decrease within the PBL is from $53 \%$ to $24 \%$. The aqueous-phase oxidation of $\mathrm{SO}_{2}$ depends on cloud fraction (CF) and cloud water contents. The change in low-level CFs in MERRA $(1000-700 \mathrm{hPa})$ is shown in Fig. 9b. There was an $80 \%$ reduction in $\mathrm{CF}$ over $\mathrm{TX}$ as well as in parts of the eastern SUS. The change in CF had a high correlation of 0.8 with that of sulfate production. In addition, higher temperatures during the drought favored the formation of sulfate, resulting in mitigation of sulfate decrease over the northern part of TX where temperatures showed the highest increase during the drought (cf. Fig. 1c).

Total sulfur deposition was reduced by $36 \%$ during the drought month, attributed mainly to a $0.25 \mathrm{ktS}$ day $^{-1}$ decrease of wet deposition. The reduction of wet deposition was significant at both the surface and PBL. The 
spatial patterns of precipitation decreases affected sulfate wet deposition. Over New Mexico, where it is relatively dry (11.6 $\mathrm{mm}^{\text {month }}{ }^{-1}$ rainfall in normal conditions), the number of precipitation days decreased from 2 to 0 during the drought month, resulting in a $100 \%$ reduction in wet deposition on these days. Over central Texas, the number of precipitation days decreased from 23 in June 2010 to 4 in June 2011, resulting in a 58\% reduction in the amount of precipitation and $50 \%$ reduction in sulfate wet deposition. Over the wetter Southeast, in spite of a 30\% reduction in precipitation, the amount of precipitation is still high at $111 \mathrm{~mm}$ month ${ }^{-1}$ with 22 precipitation days in June 2011. Sulfate wet deposition fluxes showed an increase over this region in response to increasing sulfate burdens in June 2011. Horizontal and vertical transport all together contributed to net outflow of $0.55 \mathrm{kt} \mathrm{S}$ day $^{-1}$ for $\mathrm{SO}_{2}$ and $0.16 \mathrm{kt} \mathrm{S}$ day $^{-1}$ for sulfate in 2011. Increasing southerly winds during the drought was responsible for the enhanced outflow of total sulfur.

Through the budge analysis, we conclude that drought results in a large decrease of aqueous-phase oxidation of sulfate over TX, which outweighs the combined effects of decreased wet deposition and decreased outflow, especially at the surface, contributing to a decrease of sulfate both at the surface and within the PBL over the TX region.

\section{Conclusions and discussion}

In this study, we characterized and quantified the impact of the 2011 severe drought in the southern United States on summertime surface $\mathrm{PM}_{2.5}$ concentrations through comparative analysis between June 2010 (the normal month) and June 2011 (the drought month). Analysis of surface observations revealed a $26 \%$ enhancement of $\mathrm{PM}_{2.5}$ over SUS under the drought influence, which is attributed to a $119 \%$ increase in OC, and a $10.7 \%$ decrease of $\mathrm{PM}_{2.5}$ over TX driven by a $26 \%$ decrease in sulfate. Observations also indicated a $60 \%$ increase of EC and a $24 \%$ increase of dust, but their contributions to the overall $\mathrm{PM}_{2.5}$ changes were smaller than $\mathrm{OC}$ and sulfate.

The GEOS-Chem model reproduced the observed spatial variations of $\mathrm{PM}_{2.5}$ changes during the drought, simulating a relative enhancement of $19 \%$ in $\mathrm{PM}_{2.5}$ over SUS and a $29 \%$ decrease over TX. The model successfully identified the OC increase and sulfate decrease as the key driver of the overall $\mathrm{PM}_{2.5}$ change over SUS and TX, respectively, demonstrating its ability in capturing some key mechanisms of drought impact on $\mathrm{PM}_{2.5}$ and its major components. Budget analysis based on the model showed that over the SUS region, direct emissions and transboundary inflow from Mexico were more important than other processes in determining the extent of OC enhancements during the drought. Influenced by the severe drought in June 2011, OC emissions from wildfires increased by a factor of 7 and BVOCs emissions were higher by $12 \%$ primarily because of higher temperatures. Inflow from Mexico was 2.5 times larger than the normal condition, resulting from increased wildfire activities in the drought-stricken Mexico and higher southerly winds. Over TX where sulfate is the dominant component of $\mathrm{PM}_{2.5}$, a large reduction of low clouds during the drought strongly inhibit the aqueous-phase oxidation of $\mathrm{SO}_{2}$ to sulfate, which offset the drought-induced decrease of sulfate wet deposition and was the key driver for decreasing sulfate both at the surface and within the PBL.

The model was able to reproduce the observed increases of dust associated with reduced soil moisture and increased wind speeds under drought conditions. Yet the model overestimates dust concentrations by $\sim 130 \%$ because of inappropriate PSD parameterization and possible biases in transport and deposition process. The model did not reproduce the change of nitrate or ammonia. Future improvement in the dust PSD scheme and the $\mathrm{HNO}_{3}$ oxidation mechanism as well as more accurate emission inventories is needed in order to improve the model's predictability skills of the drought's impact on $\mathrm{PM}_{2.5}$ and to obtain more comprehensive understanding on the response of $\mathrm{PM}_{2.5}$ to the potentially increasing drought threats in the US.

This study, focusing on a single severe drought event in the southern United States, indicates significant and complex impacts of drought on surface $\mathrm{PM}_{2.5}$ concentrations. Whether drought results in a decrease or increase of $\mathrm{PM}_{2.5}$ is determined by the balance between different responses of major $\mathrm{PM}_{2.5}$ species to drought conditions as well as the balance between the responses of sources and sinks to drought. More case studies are warranted for different regions, such as the 2014 severe drought over the western United States or the 2009 drought over southwestern China, in order to derive a comprehensive and quantitative understanding on the present-day sensitivity of $\mathrm{PM}_{2.5}$ to drought. Such an understanding will lay the scientific foundation to predict the extent to which PM air quality will be impacted by an increase in the frequency of droughts predicted in the context of global climate change.

Acknowledgments. The authors at Tsinghua University acknowledge support by the National Key Basic Research Program of China (2013CB956603 and 2014CB441302). We thank the individuals involved in making observations at the IMPROVE, U.S. EPA, and NADP networks. 


\section{REFERENCES}

Allen, C. D., and Coauthors, 2010: A global overview of drought and heat-induced tree mortality reveals emerging climate change risks for forests. For. Ecol. Manage., 259, 660-684, doi:10.1016/j.foreco.2009.09.001.

Bey, I., and Coauthors, 2001: Global modeling of tropospheric chemistry with assimilated meteorology: Model description and evaluation. J. Geophys. Res., 106, 23 073-23 095, doi:10.1029/ 2001JD000807.

Chen, D., Y. Wang, M. B. McElroy, K. He, R. M. Yantosca, and P. L. Sager, 2009: Regional CO pollution and export in China simulated by the high-resolution nested-grid GEOSChem model. Atmos. Chem. Phys., 9, 3825-3839, doi:10.5194/ acp-9-3825-2009.

Combs, S., 2012: The impact of the 2011 drought and beyond. Texas Comptroller of Public Accounts Data Division Services Publ. 96-1704, 16 pp. [Available online at http://www.window.state. tx.us/specialrpt/drought/pdf/96-1704-Drought.pdf.]

Cooke, W., C. Liousse, H. Cachier, and J. Feichter, 1999: Construction of a $1^{\circ} \times 1^{\circ}$ fossil fuel emission data set for carbonaceous aerosol and implementation and radiative impact in the ECHAM4 model. J. Geophys. Res., 104, 22 137-22162, doi:10.1029/1999JD900187.

Dai, A., 2013: Increasing drought under global warming in observations and models. Nat. Climate Change, 3, 52-58, doi:10.1038/ nclimate1633.

—_, F. Giorgi, and K. E. Trenberth, 1999: Observed and modelsimulated diurnal cycles of precipitation over the contiguous United States. J. Geophys. Res., 104, 6377-6402, doi:10.1029/ 98JD02720.

Dawson, J. P., P. J. Adams, and S. N. Pandis, 2007: Sensitivity of $\mathrm{PM}_{2.5}$ to climate in the Eastern US: A modeling case study. Atmos. Chem. Phys., 7, 4295-4309, doi:10.5194/acp-7-4295-2007.

Evans, M. J., and D. J. Jacob, 2005: Impact of new laboratory studies of $\mathrm{N}_{2} \mathrm{O}_{5}$ hydrolysis on global model budgets of tropospheric nitrogen oxides, ozone, and OH. Geophys. Res. Lett., 32, L09813, doi:10.1029/2005GL022469.

Fairlie, T. D., D. J. Jacob, and R. J. Park, 2007: The impact of transpacific transport of mineral dust in the United States. Atmos. Environ., 41, 1251-1266, doi:10.1016/j.atmosenv.2006.09.048.

Flanagan, J. B., R. K. M. Jayanty, E. E. Rickman Jr., and M. R. Peterson, 2006: $\mathrm{PM}_{2.5}$ Speciation Trends Network: Evaluation of whole-system uncertainties using data from sites with collocated samplers. J. Air Waste Manage. Assoc., 56, 492-499, doi:10.1080/10473289.2006.10464516.

Fountoukis, C. and A. Nenes, 2007: ISORROPIA II: A computationally efficient thermodynamic equilibrium model for $\mathrm{K}^{+}-\mathrm{Ca}^{2+}-\mathrm{Mg}^{2+}-\mathrm{NH}_{4}^{+}-\mathrm{Na}^{+}-\mathrm{SO}_{4}^{2-}-\mathrm{NO}_{3}^{-}-\mathrm{Cl}^{-}-\mathrm{H}_{2} \mathrm{O}$ aerosols. Atmos. Chem. Phys., 7, 4639-4659, doi:10.5194/acp-7-4639-2007.

Giglio, L., J. T. Randerson, G. R. d. Werf, P. S. Kasibhatla, G. J. Collatz, D. C. Morton, and R. S. DeFries, 2010: Assessing variability and long-term trends in burned area by merging multiple satellite fire products. Biogeosciences, 7, 1171-1186, doi:10.5194/bg-7-1171-2010.

Guenther, A., T. Karl, P. Harley, C. Wiedinmyer, P. I. Palmer, and C. Geron, 2006: Estimates of global terrestrial isoprene emissions using MEGAN (Model of Emissions of Gases and Aerosols from Nature). Atmos. Chem. Phys., 6, 3181-3210, doi:10.5194/ acp-6-3181-2006.

Heald, C. L., and Coauthors, 2012: Atmospheric ammonia and particulate inorganic nitrogen over the United States. Atmos. Chem. Phys., 12, 10295-10312, doi:10.5194/acp-12-10295-2012.
Hering, S. V., and G. R. Cass, 1999: The magnitude of bias in the measurement of $\mathrm{PM}_{2.5}$ arising from volatilization of particulate nitrate from Teflon filters. J. Air Waste Manage. Assoc., 49, 725-733, doi:10.1080/10473289.1999.10463843.

Hyslop, N., 2008: An evaluation of Interagency Monitoring of Protected Visual Environments (IMPROVE) collocated precision and uncertainty estimates. Atmos. Environ., 42, 26912705, doi:10.1016/j.atmosenv.2007.06.053.

Johnson, M. S., N. Meskhidze, and V. Praju Kiliyanpilakkil, 2012: A global comparison of GEOS-Chem-predicted and remotelysensed mineral dust aerosol optical depth and extinction profiles. J. Adv. Model. Earth Syst., 4, M07001, doi:10.1029/ 2011MS000109.

Kerr, E., 2012: Brutal drought depresses agriculture, thwarting US and Texas economies. Southwest Econ., Q4, 10-13.

Liao, H., D. K. Henze, J. H. Seinfeld, S. Wu, and L. J. Mickley, 2007: Biogenic secondary organic aerosol over the United States: Comparison of climatological simulations with observations. J. Geophys. Res., 112, D06201, doi:10.1029/ 2006JD007813.

Liu, A. Z., M. Ting, and H. Wang, 1998: Maintenance of circulation anomalies during the 1988 drought and 1993 floods over the United States. J. Atmos. Sci., 55, 2810-2832, doi:10.1175/ 1520-0469(1998)055<2810:MOCADT>2.0.CO;2.

Liu, H., D. J. Jacob, I. Bey, and R. M. Yantosca, 2001: Constraints from ${ }^{210} \mathrm{~Pb}$ and ${ }^{7} \mathrm{Be}$ on wet deposition and transport in a global three-dimensional chemical tracer model driven by assimilated meteorological fields. J. Geophys. Res., 106, 12 109-12 128, doi:10.1029/2000JD900839.

Long, D., B. R. Scanlon, L. Longuevergne, A. Y. Sun, D. N. Fernando, and H. Save, 2013: GRACE satellite monitoring of large depletion in water storage in response to the 2011 drought in Texas. Geophys. Res. Lett., 40, 3395-3401, doi:10.1002/ grl.50655.

Malm, W. C., J. F. Sisler, D. Huffman, R. A. Eldred, and T. A. Cahill, 1994: Spatial and seasonal trends in particle concentration and optical extinction in the United States. J. Geophys. Res., 99, 1347-1370, doi:10.1029/93JD02916.

Marlier, M. E., R. S. DeFries, A. Voulgarakis, P. L. Kinney, J. T. Randerson, D. T. Shindell, Y. Chen, and G. Faluvegi, 2013: El Niño and health risks from landscape fire emissions in southeast Asia. Nat. Climate Change, 3, 131-136, doi:10.1038/ nclimate1658.

Middleton, N. J., 1985: Effect of drought on dust production in the Sahel. Nature, 316, 431-435, doi:10.1038/316431a0.

$\mathrm{Mu}, \mathrm{M}$., and Coauthors, 2011: Daily and 3-hourly variability in global fire emissions and consequences for atmospheric model predictions of carbon monoxide. J. Geophys. Res., 116, D24303, doi:10.1029/2011JD016245.

NCDC, cited 2014: North American Drought Monitor (NADM) maps. [Available online at http://www.ncdc.noaa.gov/temp-andprecip/drought/nadm/nadm-maps.php?lang=en\&year $=$ 2011\&month $=6$.]

Nielsen-Gammon, J. W., 2012: The 2011 Texas drought. Tex. Water J., 3, 59-95.

Park, R. J., D. J. Jacob, B. D. Field, R. M. Yantosca, and M. Chin, 2004: Natural and transboundary pollution influences on sulfate-nitrate-ammonium aerosols in the United States: Implications for policy. J. Geophys. Res., 109, D15204, doi:10.1029/ 2003JD004473.

Prospero, J. M., and R. T. Nees, 1986: Impact of the North African drought and El Niño on mineral dust in the Barbados trade winds. Nature, 320, 735-738, doi:10.1038/320735a0. 
Räsänen, J. V., P. Yli-Pirilä, T. Holopainen, J. Joutsensaari, P. Pasanen, and M. Kivimäenpää, 2012: Soil drought increases atmospheric fine particle capture efficiency of Norway spruce. Boreal Environ. Res., 17, 21-30.

Ridley, D. A., C. L. Heald, and B. Ford, 2012: North African dust export and deposition: A satellite and model perspective. J. Geophys. Res., 117, D02202, doi:10.1029/2011JD016794.

Rienecker, M. M., and Coauthors, 2011: MERRA: NASA's ModernEra Retrospective Analysis for Research and Applications. J. Climate, 24, 3624-3648, doi:10.1175/JCLI-D-11-00015.1.

Romm, J., 2011: Desertification: The next dust bowl. Nature, 478, 450-451, doi:10.1038/478450a.

Ruminski, M. G., M. D. Fromm, and E. Ramirez, 2011: The Arizona Wallow wildfire: Monitoring its progress, extreme behavior and long range smoke transport from multiple satellite platforms. 2011 Fall Meeting, San Francisco, CA, Amer. Geophys. Union, Abstract NH52A-06.

Seager, R., L. Goddard, J. Nakamura, N. Henderson, and D. E. Lee, 2014: Dynamical causes of the 2010/11 Texas-northern Mexico drought. J. Hydrometeor., 15, 39-68, doi:10.1175/ JHM-D-13-024.1.

Seinfeld, J. H., and S. N. Pandis, 2012: Atmospheric Chemistry and Physics: From Air Pollution to Climate Change. John Wiley \& Sons, $1232 \mathrm{pp}$.

Smith, L. T., L. E. O. C. Aragão, C. E. Sabel, and T. Nakaya, 2014: Drought impacts on children's respiratory health in the Brazilian Amazon. Sci. Rep., 4, 3726, doi:10.1038/srep03726.

Svoboda, M., and Coauthors, 2002: The Drought Monitor. Bull. Amer Meteor. Soc., 83,1181-1190, doi:10.1175/1520-0477(2002)083<1181: $\mathrm{TDM}>2.3 . \mathrm{CO} ; 2$.

Tosca, M. G., J. T. Randerson, C. S. Zender, M. G. Flanner, and P. J. Rasch, 2010: Do biomass burning aerosols intensify drought in equatorial Asia during El Niño? Atmos. Chem. Phys., 10, 3515-3528, doi:10.5194/acp-10-3515-2010.

van Donkelaar, A., and Coauthors, 2008: Analysis of aircraft and satellite measurements from the Intercontinental Chemical Transport Experiment (INTEX-B) to quantify long-range transport of East Asian sulfur to Canada. Atmos. Chem. Phys., 8, 29993014, doi:10.5194/acp-8-2999-2008.
Veraverbeke, S., and S. J. Hook, 2013: Evaluating spectral indices and spectral mixture analysis for assessing fire severity, combustion completeness and carbon emissions. Int. J. Wildland Fire, 22, 707-720, doi:10.1071/WF12168.

Vijayakumar, K., P. C. S. Devara, and C. P. Simha, 2012: Aerosol features during drought and normal monsoon years: A study undertaken with multi-platform measurements over a tropical urban site. Aerosol Air Qual. Res., 12, 1444-1458, doi:10.4209/ aaqr.2012.01.0005.

Wang, J., S. A. Christopher, U. S. Nair, J. S. Reid, E. M. Prins, J. Szykman, and J. L. Hand, 2006: Mesoscale modeling of Central American smoke transport to the United States: 1. "Top-down" assessment of emission strength and diurnal variation impacts. J. Geophys. Res., 11, D05S17, doi:10.1029/ 2005JD006416.

Wang, Y. X., M. B. McElroy, D. J. Jacob, and R. M. Yantosca, 2004: A nested grid formulation for chemical transport over Asia: Applications to CO. J. Geophys. Res., 109, D22307, doi:10.1029/2004JD005237.

Weinhold, B., 2011: Fields and forests in flames: Vegetation smoke and human health. Environ. Health Perspect., 119, A386A393, doi:10.1289/ehp.119-a386.

Welch, B. L., 1938: The significance of the difference between two means when the population variances are unequal. Biometrika, 29, 350-362, doi:10.1093/biomet/29.3-4.350.

Wesely, M. L., 1989: Parameterization of surface resistances to gaseous dry deposition in regional-scale numerical models. Atmos. Res., 23, 1293-1304.

Winguth, A. M. E., and B. Kelp, 2013: The urban heat island of the north-central Texas region and its relation to the 2011 severe Texas drought. J. Appl. Meteor. Climatol., 52, 2418-2433, doi:10.1175/JAMC-D-12-0195.1.

Zhang, L., and Coauthors, 2012: Nitrogen deposition to the United States: Distribution, sources, and processes. Atmos. Chem. Phys. Discuss., 12, 241-282, doi:10.5194/acpd-12-241-2012.

, J. F. Kok, D. K. Henze, Q. Li, and C. Zhao, 2013: Improving simulations of fine dust surface concentrations over the western United States by optimizing the particle size distribution. Geophys. Res. Lett., 40, 3270-3275, doi:10.1002/grl.50591. 